\title{
MONITORING AND ENERGY MANAGEMENT APPROACH FOR A FUEL CELL HYBRID ELECTRIC VEHICLE
}

\author{
Benali TIFOUR $^{1}$, Moussa BOUKHNIFER $^{2}$, Ahmed HAFAIFA ${ }^{1,3}$, Camel TANOUGAST $^{2}$ \\ ${ }^{1}$ Applied Automation and Industrial Diagnostics Laboratory, University of Djelfa, Algeria \\ ${ }^{2}$ University of Lorraine, LCOMS, F-57000 Metz, France \\ ${ }^{3}$ Gas Turbine Joint Research Team, University of Djelfa, Algeria \\ E-mails: ba.tifour@univ-djelfa.dz, moussa.boukhnifer@univ-lorraine.fr, $\underline{\text { a. hafaifa@univ-djelfa.dz, }}$ \\ Camel.Tanougast@univ-lorraine.fr
}

\begin{abstract}
Recently, the reduction of fuels consumption is a global challenge, in particular for significant investments in the automotive sector, in order to optimize and control the parameters involved for the partial or total electrification of vehicles. Thereby, the energy management system remains the axis of progress for the development of fuel cell hybrid electric vehicles. The fuzzy controller has been widely adopted for energy monitoring, where the determination of its parameters is still challenging. In this work, this problem is investigated through a secondary development of a fuzzy energy monitoring system based on the Advisor platform and particle swarm optimization. The latter is used to determine, for different driving conditions, the best parameters that increase the fuel economy and reduce the battery energy use. As a result, five tuned fuzzy energy monitoring system models with five sets of parameters are obtained. Evaluation results confirm the effectiveness of this strategy, they also show slight differences between them in terms of fuel economy, battery state of charge variations, and overall system efficiency. However, the fuzzy energy monitoring system tuned under multiple conditions is the only one that can guarantee the minimum of the state of charge variations, no matter the driving conditions.
\end{abstract}

Keywords: Energy Monitoring, Fuel Cell Hybrid, Particle Swarm, Fuel Economy, Fuzzy Logic.

$\begin{array}{ll}\text { Nomenclatures } & \\ \text { FCHEV } & \text { Fuel Cell Hybrid Electric Vehicle } \\ \text { EMS } & \text { Energy Management System } \\ \text { PTC_ADV } & \text { Power Tracking Controller based } \\ & \text { Advisor } \\ \text { FC } & \text { Fuel Cell } \\ \text { PEM } & \text { Proton exchange membrane fuel cell } \\ \text { BAT } & \text { Battery } \\ \text { SC } & \text { Super Capacitor } \\ \text { PFS } & \text { Power Following Strategy } \\ \text { GA } & \text { Genetic Algorithm } \\ \text { DP } & \text { Dynamic Programming } \\ \text { PMP } & \text { Pontryagin's Minimum Principle } \\ \text { PSO } & \text { Particle Swarm Optimization } \\ \text { WSO } & \text { Weighted Sum of Objectives } \\ \text { FLC } & \text { Fuzzy Logic Control } \\ \text { FUZ.TUN (.) } & \text { Fuzzy Tuned Function of n Driving } \\ & \text { Cycle } \\ \text { VL } & \text { Very Low } \\ \text { L } & \text { Low } \\ \text { M } & \text { Medium } \\ \text { H } & \text { High } \\ \text { VH } & \text { Very High } \\ \text { PFC } & \text { Power Fuel Cell } \\ \text { MPG } & \text { Mile Per Gallon } \\ \text { SOC } & \text { State Of Charge } \\ \text { SOH } & \text { State Of Health } \\ \Delta \text { SOC } & \text { Difference between the SOC at the } \\ \text { SD SOC } & \text { start time and at the end of the cycle } \\ & \text { Standard Deviation of the SOC } \\ & \end{array}$

$\begin{array}{ll}C_{b a t} & \text { Battery capacity } \\ E_{V_{-} \text {cons }} & \text { Vehicle energy consumption } \\ P_{r e q} & \text { Required power } \\ v & \text { Vehicle speed } \\ \eta_{t} & \text { Transmission efficiency } \\ M & \text { Mass of the vehicle } \\ g & \text { Acceleration due to gravity } \\ f_{r} & \text { Rolling resistance coefficient } \\ \alpha & \text { Slope angle of the road } \\ \rho_{a} & \text { Air density } \\ C_{D} & \text { Aerodynamic drag coefficient } \\ A_{f} & \text { Cross sectional area of the vehicle } \\ \delta & \text { Rotational inertia factor } \\ F(x) & \text { Fitness function } \\ N & \text { Number of the driving cycles } \\ J_{n}(x) & \text { Objective function } \\ g_{i, n}(x) & \text { Constraints for n driving cycle } \\ E f f & \text { Overall efficiency } \\ \text { UDDS } & \text { Urban Dynamometer Driving } \\ \text { NEDC } & \text { Schedule } \\ \text { HWFET } & \text { Highway Fuel Economy Test } \\ \text { WLTP Class } & \text { 3a Worldwide Harmonized Light } \\ \text { MULTI } & \text { Vehicles Test Procedure Class 3a } \\ & \text { Multi Driving Cycles }\end{array}$




\section{INTRODUCTION}

Despite the predominance of the conventional car in the transportation industry, the number of eco-friendly cars manufactured became recently more significant. The fuel cell hybrid electric vehicle (FCHEV) is one of the best candidates to lead the future automotive market. Besides the zero $\mathrm{CO}_{2}$ emission of the FCHEVs, they have many advantages that make them more competitive. Even though they are in need of improvement, they are more efficient than conventional vehicles, they have a short refueling time, and they have a large driving range [16].

The FCHEV requires a fuel cell as the main power source and an additional storage source. It also requires an energy management system (EMS) that plays a crucial role in controlling the power between sources in order to ensure the vehicle's performance. It has a major impact on improving the fuel economy [13].

Numerous studies focusing on these strategies used in fuel cell hybrid systems have been reported in the energy storage industry literature. Recently in 2020, Cao Y. et al. in [2] realized a hybrid PV / fuel cell system optimized by metaheuristic techniques for the electric supply of a wind turbine and Radaideh MI. et al. in [14] have optimized the design of hybrid fuel cell systems under operating constraints for the purposes of energy production and cooling. Also in 2019, Wang Y. et al. in [22] proposed an energy management system for a hybrid fuel cell / battery vehicle, integrating the degradation of fuel cells and the battery in the maintenance aspect of this type of system.

Indeed, Guo J. et al. in [5] proposed a modern method of energy management in real time for a hybrid electric vehicle in the same direction Mehta $\mathrm{R}$. et al. in [10] realized an intelligent system for the energy management of electric vehicles and $\mathrm{Wu} \mathrm{X}$. et al. in [24] applied an optimal control strategy for the energy management of electric vehicles and Bhatti AR. et al. in [1] carried out a technicaleconomic study based on inference rules for the energy management of electric vehicles at constant price using a photovoltaic network system. Regarding the studies of energy management systems, they can be classified into two main categories: rules based and optimization based.

The EMS based on fuzzy logic control (FLC) is one of the most popular methods, it has attracted many researchers [7, 9, 11 25-26]. It has many advantages, being simple, robust and flexible when the model is nonlinear. However, this strategy cannot be efficient if the driving profile is not previously known, therefore it cannot have optimal results in practice. In addition, most of the research results are based on simulations and implementation on hardware is still lacking [18]. Li Q. et al. in [9] implemented an FLC model in the Advisor platform. They proposed two structures: FC/BAT and FC/BAT/SC in order to increase the fuel economy and the mileage considering driving modes to design the fuzzy parameters. Results show better performances for these two proposed structures than the power tracking controller (PTC_ADV) embedded in the Advisor software. Hemi et al. in [6] propose three configurations: FC/BAT, FC/SC and FC/BAT/SC. These models are implemented in a modified Simulink model proposed by Tremblay et al. in [21]. They are evaluated in real time driving cycles, simulation results show that the proposed models satisfy the power requirement. The last configuration enables a fast charging and discharging which improves the battery lifespan. Zhang G. et al. in [25] propose a fuzzy EMS for a FC/BAT hybrid locomotive based on the Advisor software. They use the Advisor auto-optimization method to optimize the size of the FC and the Acid battery in order to improve their efficiencies and the fuel economy. They use a fuzzy model to control the power flux between these sources. A comparison of results between the developed models with the power following strategy (PFS) under a real operating subway's driving cycle shows an improvement of fuel economy, dynamic priorities, and a large increase of FC efficiency. However, the battery, as well as other components' efficiencies, decrease in comparison with PFS.

In these previous studies, the selection of the fuzzy parameters is not focused enough. However, due to the high number of the fuzzy parameters, the selection of the best parameters of the controller by trial and error is very problematic [11]. Much research focuses on this subject; Chun-Yan L. et al. in [4] propose an optimized Fuzzy EMS for a FC/BAT hybrid vehicle, where the fuzzy EMS parameters are optimized by the direct algorithm to maximize the efficiency of the fuel cell under three profiles. Results show that these parameters are close. The authors conclude that the proposed controller can be adopted on real driving conditions. Caux S. et al. in [3] present an EMS based on fuzzy and their parameters are tuned by genetic algorithm (GA) to maximize the energy economy, where the results are higher when compared to the results obtained by using dynamic programming (DP) which is considered as a reference. In order to validate these results for a real driving profile, authors apply the optimized parameters obtained for each driving profile on another profile. They conclude that the given results are to some extent acceptable. The authors interpret this as the similarity of the harmonic contents on the power profiles. Odeim F. et al. in [12] propose two real time EMSs: PI controller based on Pontryagin's minimum principle (PMP) with three parameters and fuzzy controller. They use GA to optimize its ten parameters to minimize the fuel consumption while maintaining the state of charge (SOC) deviation, with six driving cycles are engaged in the optimization process to have a further robustness on real time conditions. Results 
show the out performance of the PI strategy over the fuzzy strategy. Ravey A. et al. in [15] apply GA to define the set of fuzzy parameters to reduce the fuel consumption and maintain the SOC of the lead acid batteries at the end of the cycle the same as the SOC initial, the optimization is processed under one driving cycle. Simulation results are close to DP strategy results. However, they are lower when this strategy is applied in a real FCHEV. Kandidayeni M. et al. in [7] propose an FLC for FCHEV, they use particle swarm optimization (PSO) to find the optimal fuel cell and battery sizes and it is used again to define the optimal fuzzy parameters over different traffic patterns to reduce the fuel consumption.

The optimization results are compared with GA optimization results, this optimal controller keeps the fuel cell work at its high efficiency. At a second stage, in order to be applicable to different conditions, the fuzzy controller is tuned over the TEH-CAR driving cycle to attain the optimal fuel consumption. This study shows good results in terms of fuel consumption, despite the SOC results are not shown in this work. Zhang R. et al. in [26] develop an EMS for an FC/CS vehicle based on fuzzy system, where the fuzzy parameters are tuned by GA to minimize the fuel consumption and the fuel cell current fluctuations. The NEDC cycle, as it has the highway and urban profiles, is delegated in the optimization process. This bi-objective problem is converted to a single objective by using the weighted sum of objectives (WSO) method. Results over many driving profiles show a reduction of the current fluctuations and the fuel consumption.

In this work an energy management and monitoring strategy is presented, based on fuzzy first order of Sugueno, its membership function and weights are selected by PSO. The main objectives of this development are to tune the fuzzy EMS under different conditions to maximize the fuel economy mile per gallon (MPG) and maintain the SOC variation in the lowest range at the end of the trip while keeping the vehicle performance. The development of the fuzzy EMS model is implemented in the Advisor simulator software. Four driving cycles are engaged independently and altogether in the optimization process. Therefore, five tuned fuzzy are obtained and evaluated under the considered driving cycles.

In this paper, the second section introduces initially an overview of the proposed approach followed by a description of the FCHEV model in the Advisor. The third part will be dedicated to the development of the fuzzy EMS and the optimization process. The results will be discussed and a conclusion with future work will be presented in the last section.

\section{ENERGY MANAGEMENT AND MONITORING SYSTEM}

The electric vehicle is emerging as a strategic environmental solution to tackle one of the biggest energy challenges. However, these processes require an energy storage system, in order to improve the environmental performance of urban areas. The state of charge of the battery (SOC) is dependent on its state of aging, given by the following equation [1]:

$$
\begin{aligned}
& \operatorname{SOC}\left(t_{1}\right)=100 \cdot \frac{C_{b a t-r e s}}{C_{b a t-a c t}}=100 \cdot \frac{C_{b a t-a c t}-C_{b a t-u t i}}{C_{b a t-a c t}} \\
& \Rightarrow \operatorname{SOC}\left(t_{1}\right)=\operatorname{SOC}\left(t_{0}\right)-\frac{100}{C_{b a t-a c t}} \int_{t_{0}}^{t_{1}} i(t) d t
\end{aligned}
$$

with $\operatorname{SOC}\left(t_{0}\right)$ is the initial state charged to $100 \%$, $i(t)$ is the current flowing through the battery, $C_{\text {bat-res }}$ is the estimated residual capacity in $\mathrm{Ah}$ at $t=t_{1}, C_{b a t-a c t}$ is the current nominal capacity in Ah taking into account aging, $C_{b a t-u t i}$ is the capacity used in Ah discharged during of the cycle.

The SOC is expressed as a percentage and it is referenced to $100 \%$ when the charging current has not changed for two hours $\left(t_{0}\right)$, for charging at constant voltage and constant temperature. In a standardized way, it most often corresponds to the ratio between the residual capacity and the current nominal battery capacity. Also, the state of health of the battery ( $\mathrm{SOH}$ ) makes it possible to define its aging, it is an indicator which quantifies the reduction in performance due to the degradation of its capacity or the increase in its internal resistance, which can be determined with the following formula:

$$
S O H=100 \cdot \frac{C_{b a t-a c t}}{C_{b a t-n o m}}
$$

where $C_{b a t-a c t}$ is the nominal capacity in new condition in Ah and $C_{b a t-n o m}$ is the current nominal capacity in the cycle considered in Ah.

\subsection{System description}

As previously mentioned, this research focus on fuzzy inference variables selection and how they can be impacted by the driving conditions as well as how they can impact on the fuel consumption and the battery energy use. The Fig. 1 presents an overview of this proposed methodology, through the Advisor environment, we develop and implement a fuzzy energy management system to split the power between the fuel cell and the battery of the FCHEV. The Advisor provides a powerful tool for a fast design and analysis of different powertrains [23]. The optimization tool PSO is introduced to interact with the FCHEV model. 


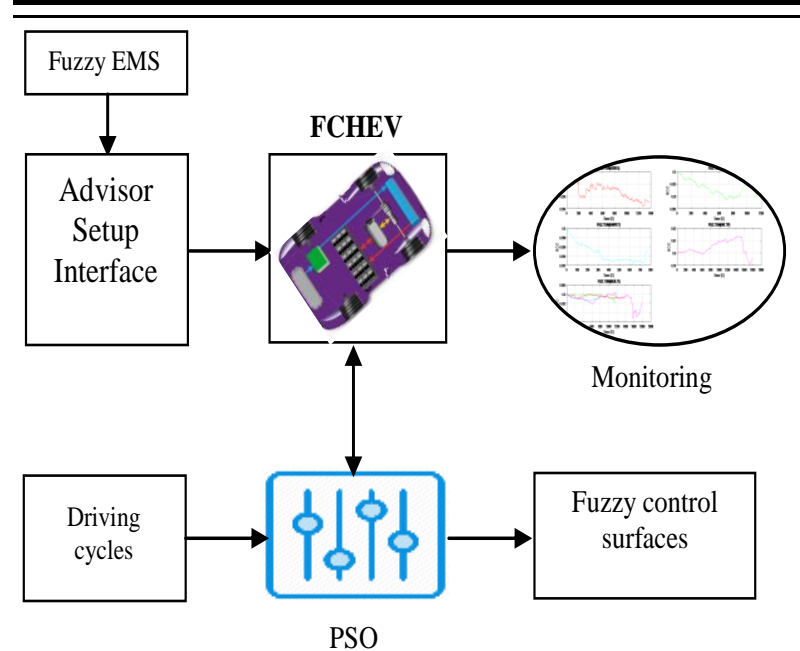

Fig. 1. Diagram of the monitoring system

The PSO is responsible for monitoring the fuzzy variables for different driving conditions, the objective function is designed to give the optimal fuel economy while maintaining the battery state of charge variation and ensuring the vehicle dynamic performance [17, 19]. Recently, the main axis of progress for the development of electric vehicles is based on the development of storage systems for on-board energy providing solutions for improving the autonomy, mass and lifespan of this type of system. Indeed, the time cycle used by the vehicle is equivalent to minimizing the discharge of the battery compared to its maximum state of charge which is the objective function, given by:

$$
J(x)=\min _{(x)} \sum_{(u, v)} C_{u, v} x_{u, v}
$$

where $x_{u, v}$ is the indicating variable selected, $C_{u, v}$ is the associated energy cost.

However, electric vehicles are equipped by several electronic components and are exposed to direct electrical risks, even in the event of a breakdown. A good monitoring strategy, based on the control of their energy variables is necessary to eliminate and minimize breakdowns and the presence of failures. The implementation of such objectives requires detailed studies in order to define, optimize and control these parameters involved. In this work, the best parameters for each case are saved in the Advisor for assessment.

\subsection{Fuel cell battery model}

The FCHEV, shown in Fig. 2, is mainly composed of the traction motor, the fuel cell (PEM), the battery pack, the DC/DC power converter and the EMS [23].

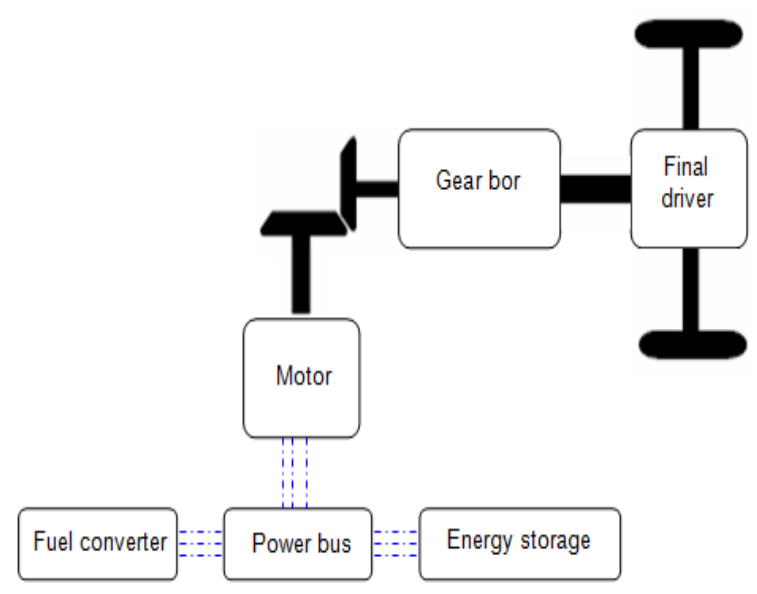

Fig. 2. FCHEV configuration in Advisor

The traction motor provides the propulsion power of the vehicle, the size of the motor should be selected by calculating the maximum power required from the equation:

$$
\begin{aligned}
& P_{r e q}=\frac{V}{1000 \eta_{t}}\left(M g f_{r} \cos (\alpha)+\frac{1}{2} \rho_{a} C_{D} A_{f} V^{2}\right. \\
& \left.+M g \sin (\alpha)+M \delta \frac{d v}{d t}\right)
\end{aligned}
$$

where $P_{r e q}, v, \eta_{t}, M, g, f_{r}, \alpha, \rho_{a}, C_{D}, A_{f}$, $\delta$ are respectively the required power, the vehicle speed, the transmission efficiency, the mass of the vehicle, the acceleration due to gravity, the rolling resistance coefficient, the slope angle of the road, the density of air, the aerodynamic drag coefficient, the cross-sectional area of the vehicle, and the rotational inertia factor.

The energy consumed is obtained by integrating the power of the vehicle with respect to the travel time $\left(t_{c y}\right)$, given by:

$$
E_{V_{-} \text {cons }}=\int_{0}^{t_{c y}} P_{V}(t) d t
$$

The power and energy consumptions of an FCHEV depend on the driving cycle, but also on the characteristics of the vehicle in terms of weight, volume, coefficient of penetration into the air [12].

The fuel cell is the principal source providing the most power required by the traction motor, the battery as an additional source assists the fuel cell to improve its performances and stores the braking energy, which increases the system efficiency. In this paper the specifications of the FCHEV in Advisor are summarized in Table 1 [20]. It should be noted the sizing of the components has not been considered in this study. 
Tifour B., Boukhnifer M., Hafaifa A., Tanougast C.: Monitoring and control of energy management system ...

\begin{tabular}{|c|c|c|c|}
\hline \multicolumn{4}{|c|}{ Table 1. The FCHEV parameters in Adviso } \\
\hline \multicolumn{4}{|l|}{ Vehicle } \\
\hline Mass (kg) & 592 & $\eta[\%]$ & 90 \\
\hline Cargo Mass (kg) & 136 & $\delta$ & 1.043 \\
\hline Center-Height (m) & 0.5 & $g\left[m s^{-1}\right]$ & 9.81 \\
\hline Wheelbase $(\mathrm{m})$ & 2.6 & $A_{f}\left[m^{2}\right]$ & 2 \\
\hline Air density & - & $\rho_{a}\left[\mathrm{Kgm}^{-1}\right]$ & 1.202 \\
\hline \multicolumn{4}{|l|}{ Motor } \\
\hline Type & $\begin{array}{l}\mathrm{AC} \\
\text { Induction }\end{array}$ & $\begin{array}{l}\text { Max Power } \\
{[\mathrm{kW}]}\end{array}$ & 100 \\
\hline Mass (kg) & 122 & Peak efficiency & 0.92 \\
\hline \multicolumn{4}{|l|}{ Fuel Cell } \\
\hline Type & PEM & $\begin{array}{l}\text { Max Power } \\
{[\mathrm{kW}]}\end{array}$ & 50 \\
\hline Mass (kg) & 223 & Peak efficiency & 0.6 \\
\hline \multicolumn{4}{|l|}{ Battery } \\
\hline Type & $\begin{array}{l}12 \mathrm{~V} 26 \\
\mathrm{Ah} \\
10 \mathrm{EP} \\
\text { VRLA }\end{array}$ & $\begin{array}{l}\text { Max Capacity } \\
\text { [Ah] }\end{array}$ & 45 \\
\hline Mass (kg) & 495 & Voltage [v] & 12 \\
\hline
\end{tabular}

\section{FUZZY DEVELOPMENT AND PSO}

\subsection{Fuzzy logic model}

The Fuzzy logic has been commonly used as a controller in energy management systems, it has many advantages, it is based on If-Then rules and membership functions which imply the knowledge of human expertise, it doesn't require the exact model of the system and it has an inherent robustness [19].

The proposed EMS model is the first order Sugeno fuzzy that is implemented with two inputs and one output. The inputs variables are the required propulsion power $P_{r e q}$ and the state of charge of the battery SOC. The output variable is the fuel cell reference power (PFC). The input $P_{r e q}$ consists of 5 Fuzzy subsets; VL: Very Large, L: Large, M: Medium, H: High, VH: Very High. Its domain of discourse is between $\left[\begin{array}{ll}P_{r e q, \text { min }} & P_{r e q, \max }\end{array}\right]$, taking into account the braking and the acceleration power. The input SOC consists of 3 fuzzy subsets $\{\mathrm{L} \mathrm{M} \mathrm{H}\}$, with the range of discourse between [0 1]. The output PFC has the range of $\left[\begin{array}{ll}0 & P F C_{\max }\end{array}\right]$; it includes 5 fuzzy subsets; VL: \{VL L M H VH\}. The trapezoidal shape is chosen to describe each of all of the linguistic variables. Therefore the fuzzy inference system is formulated by 15 rules which are summarized in Table 2. The typical rule in a Sugeno fuzzy model has the form:

$$
\begin{aligned}
& \text { If Input } 1 \text { is } x \text { and Input } 2 \text { is } y \text {, } \\
& \text { then the output is } z=\text { pix }+q i y+r i
\end{aligned}
$$

For a zero order Sugeno model, the output level $z$ is a constant ( $p=q=0)$, each rule weights its output level $z_{i}$, by the firing strength of the rule $w_{i}$. The final output of the system is the weighted average of all rule outputs, computed as:

$$
Z=\frac{\sum_{i=1}^{N} W_{i} \cdot Z_{i}}{\sum_{i=1}^{N} W_{i}}
$$

where $N$ is the number of rules.

The model is set up to be compatible with Advisor blocks and it can be embedded into the hybrid vehicle model as shown in Fig. 3. To make the model work properly and loaded from the setup screen, the following steps are necessary:

Step1: Create the proposed model with Simulink blocks and match the inputs and the outputs the same as the existing control models

Step2: Create a fuzzy system with the interpreted Simulink Matlab function block

Step3: Unlock the Advisor control library to log the new subsystem

Step4: Create a new file in Advisor control folder including the name of the new controller and all power train control parameters, including gearbox, clutch, hybrid, and engine controls

Step5: Make changes to the existed Advisor function by adding the new controller in the block choice list, this function is responsible to set all the configurable subsystems to their proper choices for the current block diagram [20].

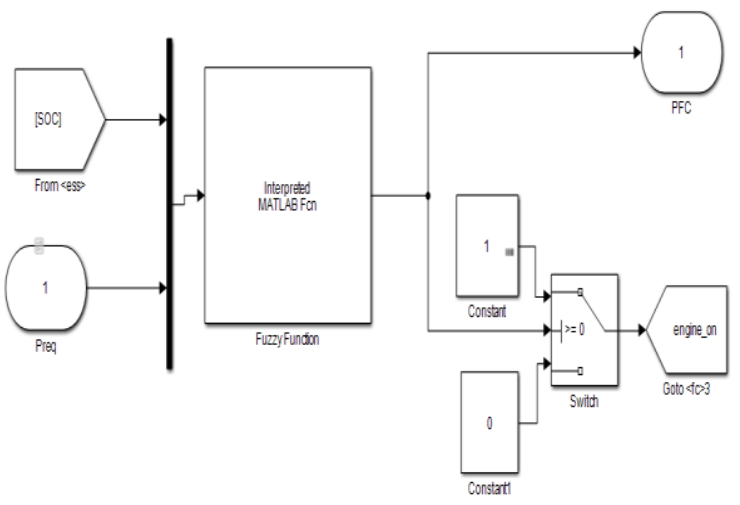

Fig. 3. Fuzzy EMS Simulink model in Advisor

Table 2. Rules table

\begin{tabular}{|c|c|c|c|c|c|c|}
\hline \multirow{2}{*}{\multicolumn{2}{|c|}{ PFC }} & \multicolumn{5}{|c|}{$P_{\text {req }}$} \\
\cline { 3 - 7 } & VL & L & M & H & VH \\
\hline \multirow{2}{*}{$\circlearrowleft$} & L & L & M & H & H & VH \\
\cline { 2 - 7 } & M & VL & L & M & H & VH \\
\cline { 2 - 7 } & H & VL & L & M & H & VH \\
\hline
\end{tabular}

\subsection{Optimization of the model by particle swarm}

As previously stated, it is critical to determine by trial and error the fuzzy parameters to improve the EMSs performances. However, using tools of optimization should be effective [18]. Many 
researchers have been introducing these tools to optimize the fuzzy parameters such as genetic algorithm GA and PSO. Hence PSO is chosen to tune the fuzzy parameters. It is extremely simple and powerful [8].

\subsubsection{Problem formulation}

The average fuel economy that is given by MPG is chosen as the objective function that has to be maximized, it has been defined as:

$$
J(x)=\max (M P G)
$$

To satisfy the vehicle performances, PSO must evaluate the objective function with constraints, the PSO requires the prior setting of several monitoring parameters depending on the problem considered. Hence, the performance of PSO has a strong correlation with the adjustment of these parameters. The mathematical model of PSO is simple by defining these concepts on every iteration of the PSO position and the velocity of every particle is updated according into this simple mechanism. The particle moves toward a new position by using all these vectors. The new updated position denoted by $\vec{x}_{i}(t+1)$ it's the new position with a new velocity denoted by $\vec{v}_{i}(t+1)$. The mathematical model of motion of particles in the PSO can be described as follows:

$$
\begin{aligned}
& v_{i}(t+1)=w v_{i}(t)+c_{i} r_{i}\left(p_{i}(t)-x_{i}(t)\right) \\
& +c_{2} r_{2}\left(g(t)-x_{i}(t)\right)
\end{aligned}
$$

With:

$$
x_{i}(t+1)=x_{i}(t)+v_{i}(t+1)
$$

Where $i$ is the index of the particle, $v_{i}(t)$ is the velocity of particle $i$ at time $t$ and $x_{i}(t)$ is the position of particle $i$ at time $t$, the parameters $w$, $c_{1}$ and $c_{2}$ are user supplied coefficients, $r_{1}$ and $r_{2}$ are random values regenerated for each velocity update. The value $p_{i}(t)$ is the individual best candidate solution for particle $i$ at time and $g(t)$ is the swarm's global best candidate solution at time $t$.

In this work, the behavioral influence of each parameter is analyzed using the PSO, in order to determine the optimal set of parameters. This represents a means to measure the quality of each solution of the objective function by seeking the optimal value. The fitness function will take this form:

$$
F(x)=-J(x)+g_{i}(x)
$$

where $F(x)$ is the fitness function, $J(x)$ is the objective function that should be negative, $g_{i}(x)$ is a group of nonlinear inequality constraints that will be evaluated by the penalty technique. Hence two constraints are considered, the difference between the state of the charge SOC at the start time and at the end of the cycle $\triangle \mathrm{SOC}$ has to be up to 0.005 , the second constraint is the difference between the available speed and the required speed that must be up to $0.62 \mathrm{~m} / \mathrm{h}$. To determine SOC values of battery current mathematically is given by:

$$
S O C=\operatorname{SOC}\left(t_{0}\right)+\frac{1}{C_{\text {rated }}} \int_{t_{0}}^{t_{0}+\tau}\left(I_{b}-I_{\text {loss }}\right) d t
$$

where $\operatorname{SOC}\left(t_{0}\right)$ is the initial state of SOC, $I_{b}$ is the battery current, $I_{\text {loss }}$ is the consumed loss current, $C_{\text {rated }}$ is the optimal capacity

\subsubsection{Optimization under multi driving cycle}

As mentioned earlier, optimal parameters selected under one driving profile may not be optimal under another one or it may affect the vehicle performances in worst cases. In this experiment, we attempt to select the best parameters that can be applied for many driving conditions, to achieve this goal, the objective function should be the sum of the objective function for each $n$ driving cycle, and therefore the fitness function should be:

$$
F_{N}(x)=\sum_{n=1}^{N}-J_{n}(x)+g_{i, n}(x)
$$

Where $F_{N}(x)$ is the fitness function, $N$ is the number of the driving cycles considered, $J_{n}(x)$, $g_{i, n}(x)$ are the objective function, the constraints for each driving cycle respectively. These constraints remain the same as defined in the previous paragraph.

\subsubsection{Fuzzy inference variables selection}

To find the best fuzzy parameters that maximize the fitness function, 32 particles are implemented in the optimization process, representing the fuzzy membership functions and the weights; (P1 to P4), (P5 to $\mathrm{P} 12)$ and (P13 to $\mathrm{P} 17)$ represent the inputs SOC, $P_{r e q}$ and the output PFC, respectively, with the trapezoidal distribution of MFs. The weights are coded into 15 particles; (P18 to P32), in each iteration, each particle represents a potential solution and it is evaluated during a test drive cycle with the objective function.

\section{OPTIMIZATION PROCEDURE}

\subsection{Driving cycles selection}

It was already known that the driving condition is one of the factors that has a significant impact on the vehicle performance. Four standard driving cycles are selected in this study for optimization and evaluation of the model, they describe different conditions, speeds and high accelerations. The UDDS describes the drive in the city, it has a low speed and large periods of stops. The NEDC 
consists of four repeated urban sequences and one extra-urban cycle. The HWFET has a high speed and no stops periods through all the cycle. The WLTP that recently replaced the NEDC for approval testing of light duty in Europe vehicles, it includes urban, extra urban and highway driving sequences. Curves, histograms and some statistical features are shown in Fig. 4-5 and Table 3, respectively. These driving cycles are commonly used for official fuel economy test. The first three are available in the Advisor library. Hence the WLTP class $3 \mathrm{a}$ is selected and added to the Advisor library as well.
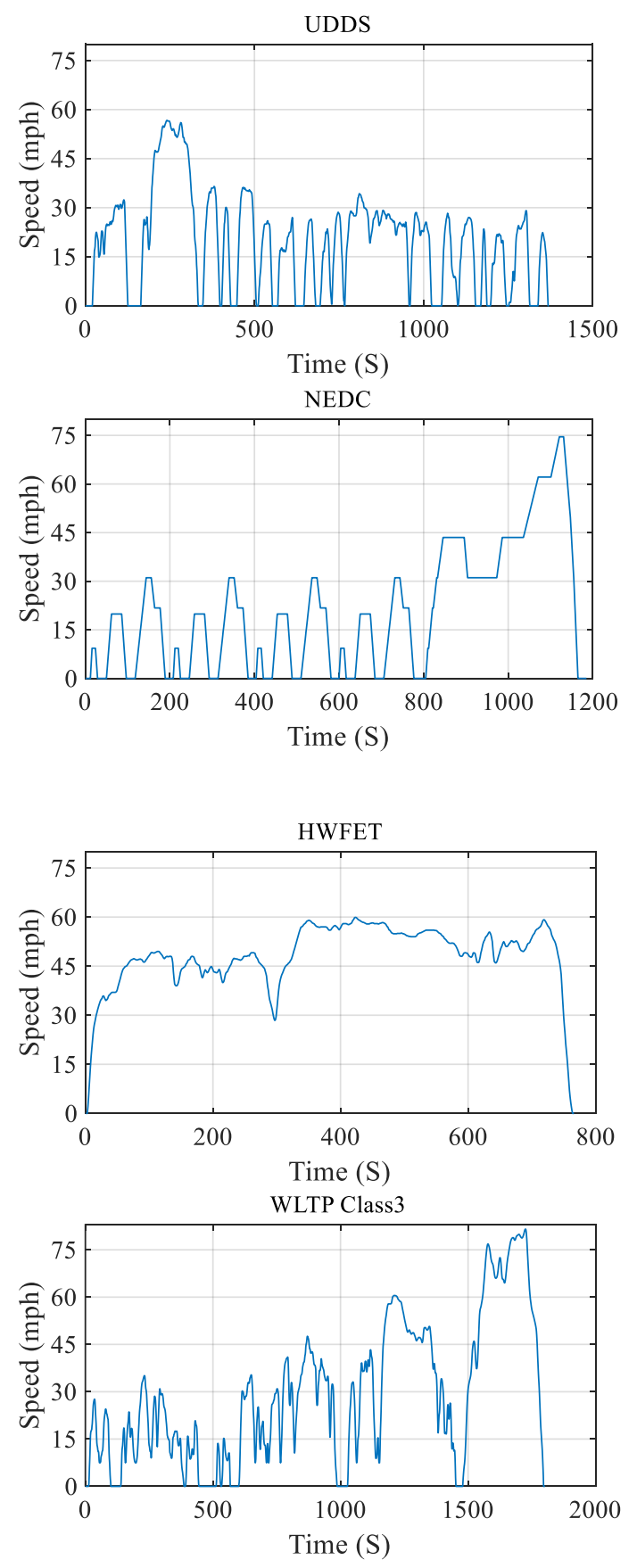

Fig. 4. Driving cycles speed curves
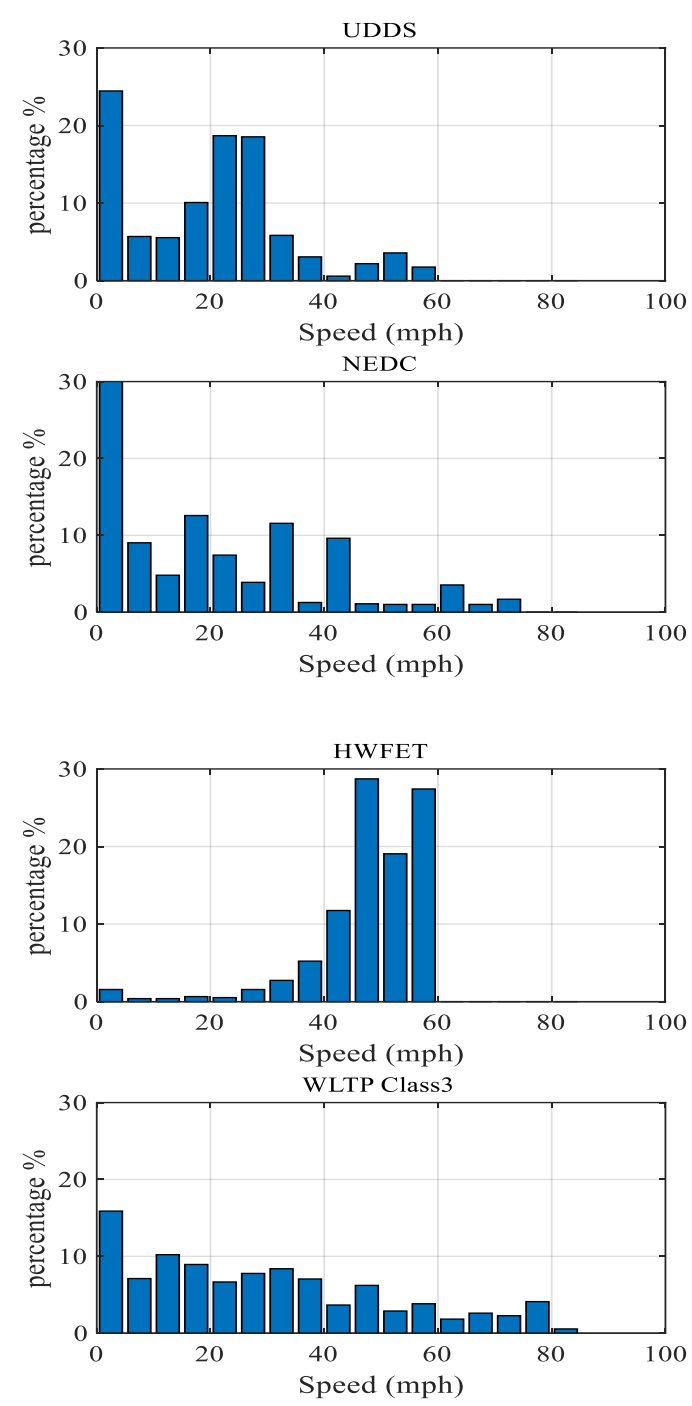

Fig. 5. Driving Cycles speed histograms

Table 3. Driving cycles Characteristics

\begin{tabular}{|l|l|l|l|l|l|l|l|}
\hline & $\begin{array}{l}\text { Dist. } \\
(\mathrm{m})\end{array}$ & $\begin{array}{l}\text { Time } \\
(\mathrm{S})\end{array}$ & $\begin{array}{l}\text { Avg. } \\
\text { Speed } \\
\mathrm{mph}\end{array}$ & $\begin{array}{l}\text { Max } \\
\text { speed } \\
\mathrm{mph}\end{array}$ & $\begin{array}{l}\text { Avg. } \\
\text { Acce. } \\
(\mathrm{ft} 2 / \mathrm{s})\end{array}$ & $\begin{array}{l}\text { Avg } \\
\text { Decel } \\
(\mathrm{ft} 2 / \mathrm{s})\end{array}$ & $\begin{array}{l}\mathrm{N} \\
\text { Stops }\end{array}$ \\
\hline UDDS & 7.45 & 1369 & 19.58 & 56.7 & 1.66 & -1.9 & 17 \\
\hline NEDC & 6.79 & 1184 & 20.64 & 74.76 & 1.78 & -2.59 & 13 \\
\hline HWFET & 10.26 & 765 & 48.2 & 59.9 & 0.64 & -0.72 & 1 \\
\hline $\begin{array}{l}\text { WLTP } \\
\text { Class3 }\end{array}$ & 14.45 & 1800 & 28.89 & 81.59 & 1.38 & -1.44 & 8 \\
\hline
\end{tabular}

\subsection{Optimization results}

The proposed algorithm is implemented and executed in Matlab. The results of the fitness function for each driving cycle and multiple driving cycles are given in Fig. 6. Table 4 summarizes the optimal variables of inputs, output and weights for the five tuned fuzzy EMSs obtained after optimization. The Fig. 7-8 respectively show the tuned inputs, the control surfaces of the five obtained models. 
Tifour B., Boukhnifer M., Hafaifa A., Tanougast C.: Monitoring and control of energy management system ...

Table 4. The optimized parameters: Inputs, output, and weights of FUZ.TUN (.)

\begin{tabular}{|c|c|c|c|c|c|}
\hline Variable & $\begin{array}{l}\text { FUZ.TUN } \\
\text { (UDDS) }\end{array}$ & $\begin{array}{l}\text { FUZ.TUN } \\
\text { (NEDC) }\end{array}$ & $\begin{array}{l}\text { FUZ.TUN } \\
\text { (HWFET) }\end{array}$ & $\begin{array}{l}\text { FUZ.TUN } \\
\text { (WLTP) }\end{array}$ & $\begin{array}{l}\text { FUZ.TUN } \\
\text { (MULTI) }\end{array}$ \\
\hline \multirow{4}{*}{$\begin{array}{c}\text { Input } 1 \\
\text { SOC }\end{array}$} & 0.56 & 0.50 & 0.58 & 0.54 & 0.59 \\
\hline & 0.61 & 0.62 & 0.63 & 0.66 & 0.61 \\
\hline & 0.78 & 0.74 & 0.75 & 0.82 & 0.72 \\
\hline & 0.89 & 0.88 & 0.87 & 0.87 & 0.89 \\
\hline \multirow{8}{*}{$\begin{array}{c}\text { Input } 2 \\
P_{r e q}\end{array}$} & 3657.45 & 4069.54 & 3408.00 & 4188.00 & 3934.66 \\
\hline & 5850.55 & 6072.24 & 5345.90 & 6027.75 & 4189.00 \\
\hline & 10055.48 & 10248.32 & 8718.19 & 8338.00 & 8338.00 \\
\hline & 18018.51 & 17496.51 & 18698.27 & 19976.95 & 19707.00 \\
\hline & 23499.64 & 24297.55 & 24242.60 & 22748.63 & 25708.21 \\
\hline & 27907.79 & 29496.88 & 29548.62 & 28265.87 & 25926.48 \\
\hline & 32161.00 & 30566.04 & 31278.67 & 31088.18 & 31801.11 \\
\hline & 32421.02 & 34460.53 & 34752.68 & 34947.00 & 32596.25 \\
\hline \multirow{5}{*}{$\begin{array}{c}\text { Output } \\
\text { PFC }\end{array}$} & 0.00 & 24.64 & 8.68 & 1.18 & 15.39 \\
\hline & 923.03 & 483.37 & 655.48 & 440.00 & 440.00 \\
\hline & 18410.89 & 19012.53 & 13653.61 & 18875.61 & 16749.66 \\
\hline & 25297.95 & 24164.19 & 24919.65 & 26004.77 & 30963.94 \\
\hline & 32485.54 & 32400.00 & 32400.00 & 33032.67 & 38643.52 \\
\hline \multirow{15}{*}{ Weights } & 0.10 & 0.10 & 0.13 & 0.10 & 0.10 \\
\hline & 1.00 & 0.32 & 0.42 & 0.95 & 0.58 \\
\hline & 0.87 & 0.27 & 0.37 & 1.00 & 0.22 \\
\hline & 0.23 & 0.53 & 0.24 & 0.79 & 0.77 \\
\hline & 0.89 & 0.80 & 0.37 & 0.10 & 0.40 \\
\hline & 1.00 & 1.00 & 0.62 & 0.38 & 0.26 \\
\hline & 0.62 & 0.10 & 0.98 & 1.00 & 0.86 \\
\hline & 0.98 & 0.41 & 1.00 & 0.72 & 1.00 \\
\hline & 0.44 & 1.00 & 1.00 & 0.53 & 0.73 \\
\hline & 0.13 & 0.17 & 0.58 & 0.34 & 0.91 \\
\hline & 0.81 & 0.25 & 0.34 & 0.33 & 0.75 \\
\hline & 0.23 & 0.23 & 0.60 & 0.10 & 0.86 \\
\hline & 0.47 & 0.10 & 0.63 & 0.10 & 1.00 \\
\hline & 0.28 & 0.97 & 0.59 & 0.14 & 0.27 \\
\hline & 0.59 & 1.00 & 0.88 & 1.00 & 0.10 \\
\hline
\end{tabular}

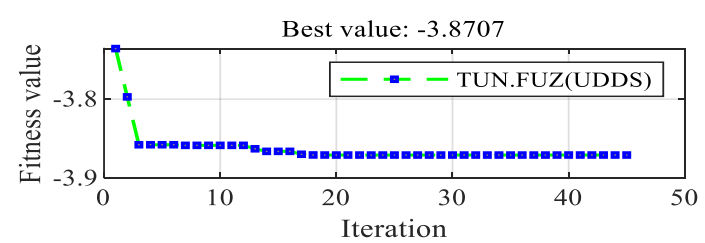

Best value: -3.9529

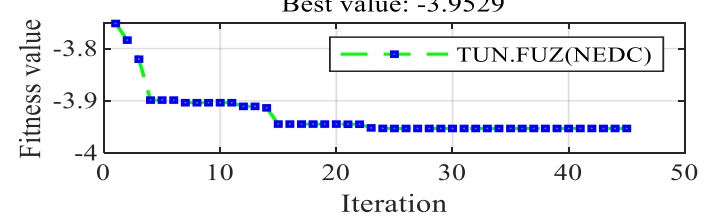

Best value: -4.8436
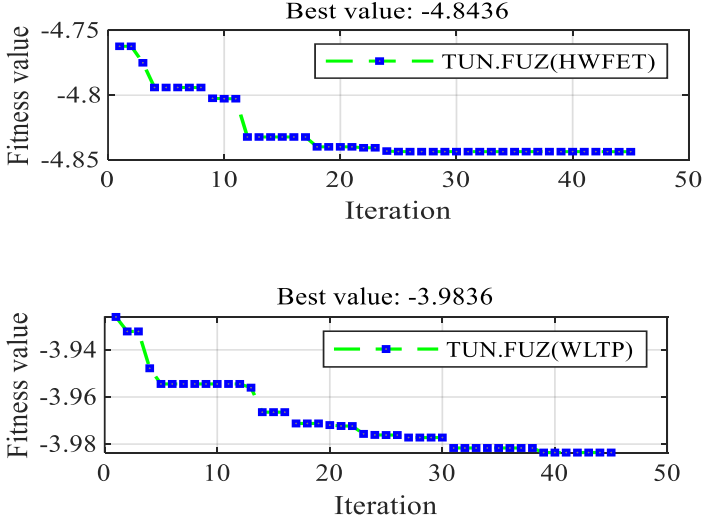

Best value: -16.2691

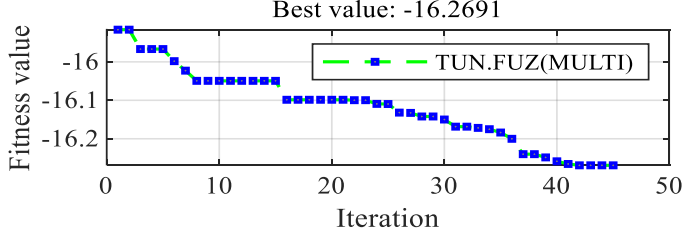

Fig. 6. Optimization process of the fitness function
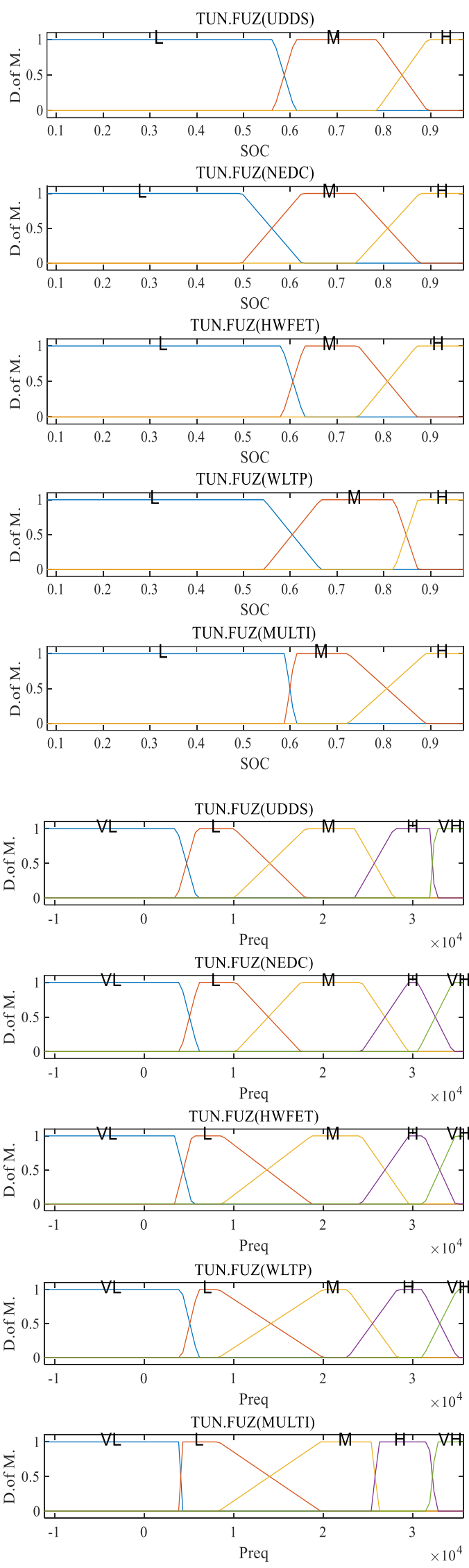

Fig. 7. Fuzzy Inputs tuned under different driving cycles 

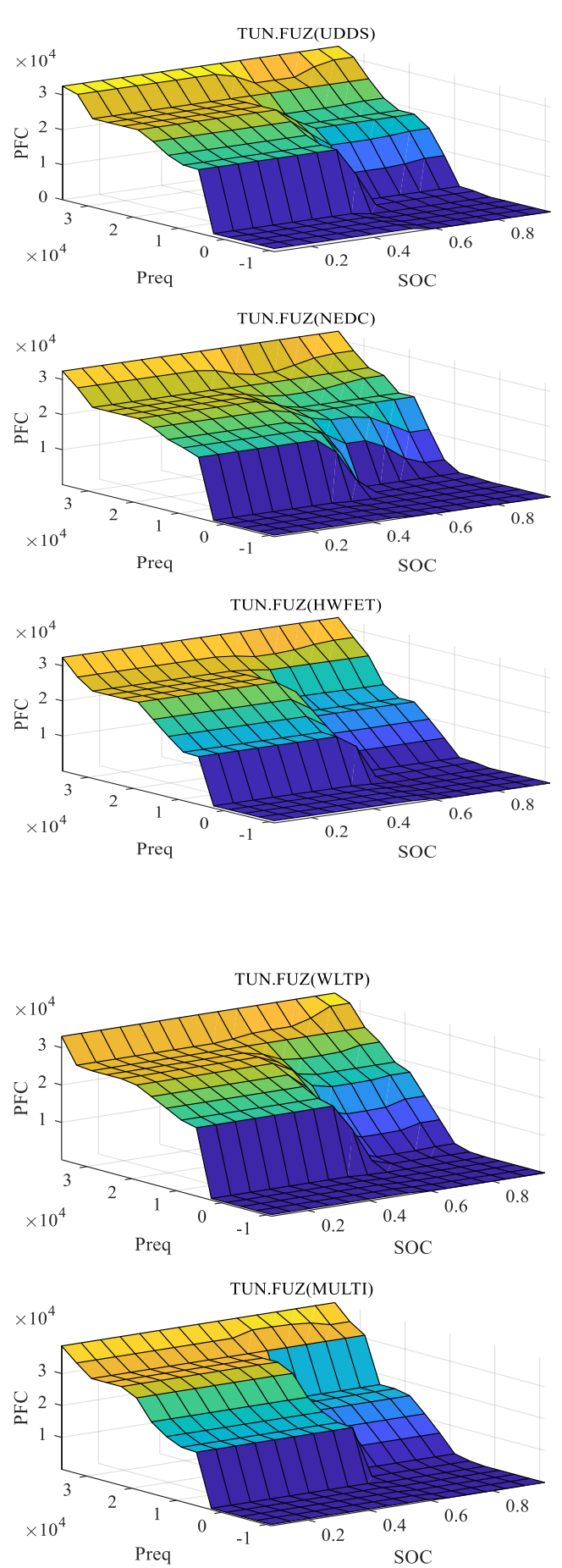

Fig. 8. Fuzzy control surfaces tuned under different driving cycles

\subsection{Results and discussions}

The obtained models are tested through the advisor software over the same driving cycles with the same initial conditions. In comparison, the FCHEV with the embedded PTC_ADV EMS based on thermostat strategy is also carried out. The Fig. 9-12 respectively present the power distribution over UDDS, NEDC, HWFET and WLTP cycles for all models, as shown in this figure, at the beginning, the battery completely provides the power to the motor because of the slow response of the fuel cell. The fuel cell power response time for all the tuned fuzzy EMSs (FUZ.TUN) is faster than the PTC.ADV. This is due to the fact that the required power is not counted in the thermostatic strategy. The battery also assists the fuel cell during the high power demand at each acceleration. The battery absorbs the energy from the fuel cell during the low power demand. It also absorbs the negative energy from the motor during the braking phases.
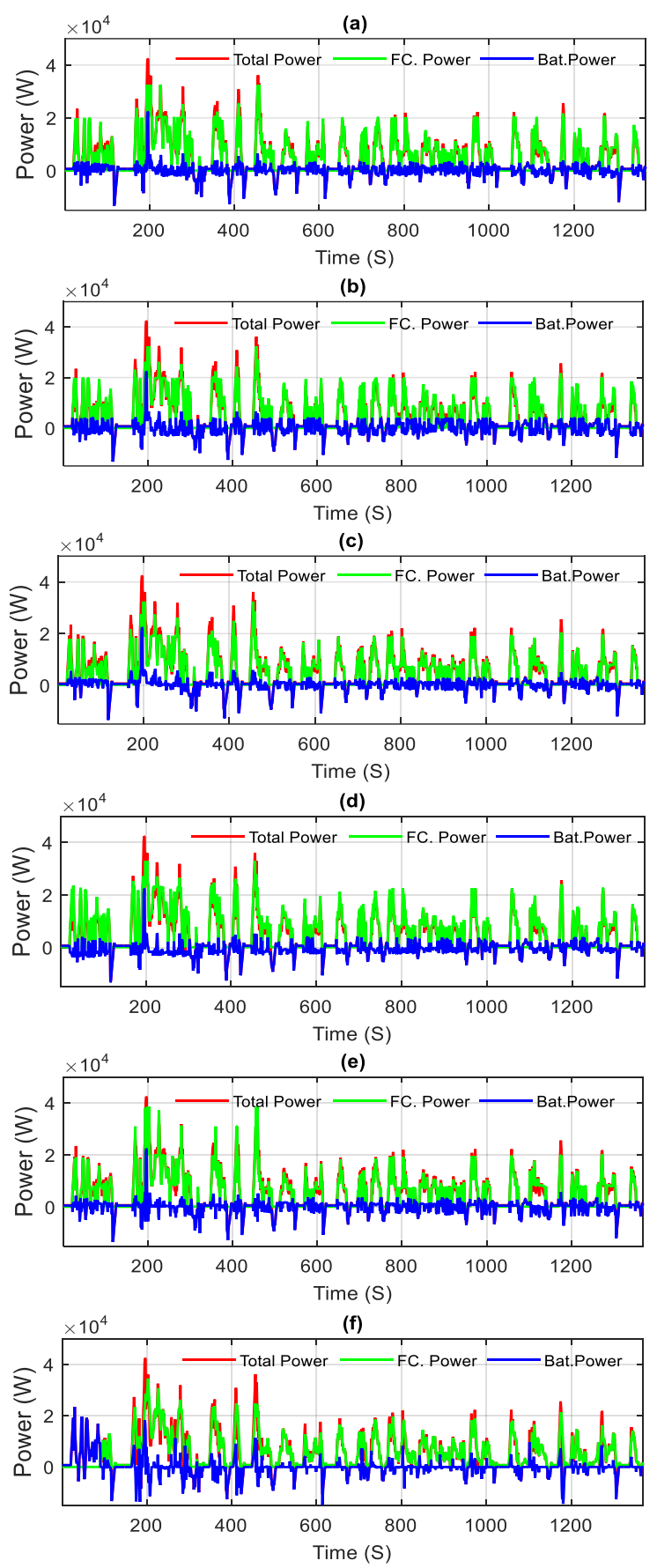

Fig. 9. Power distributions of all EMS models under UDDS: (a) FUZ.TUN (UDDS) (b) FUZ.TUN (NEDC)
(c) FUZ.TUN (HWFET)
(d) FUZ.TUN (WLTP)
(e) FUZ.TUN (MULTI)
(f) PTC_ADV 

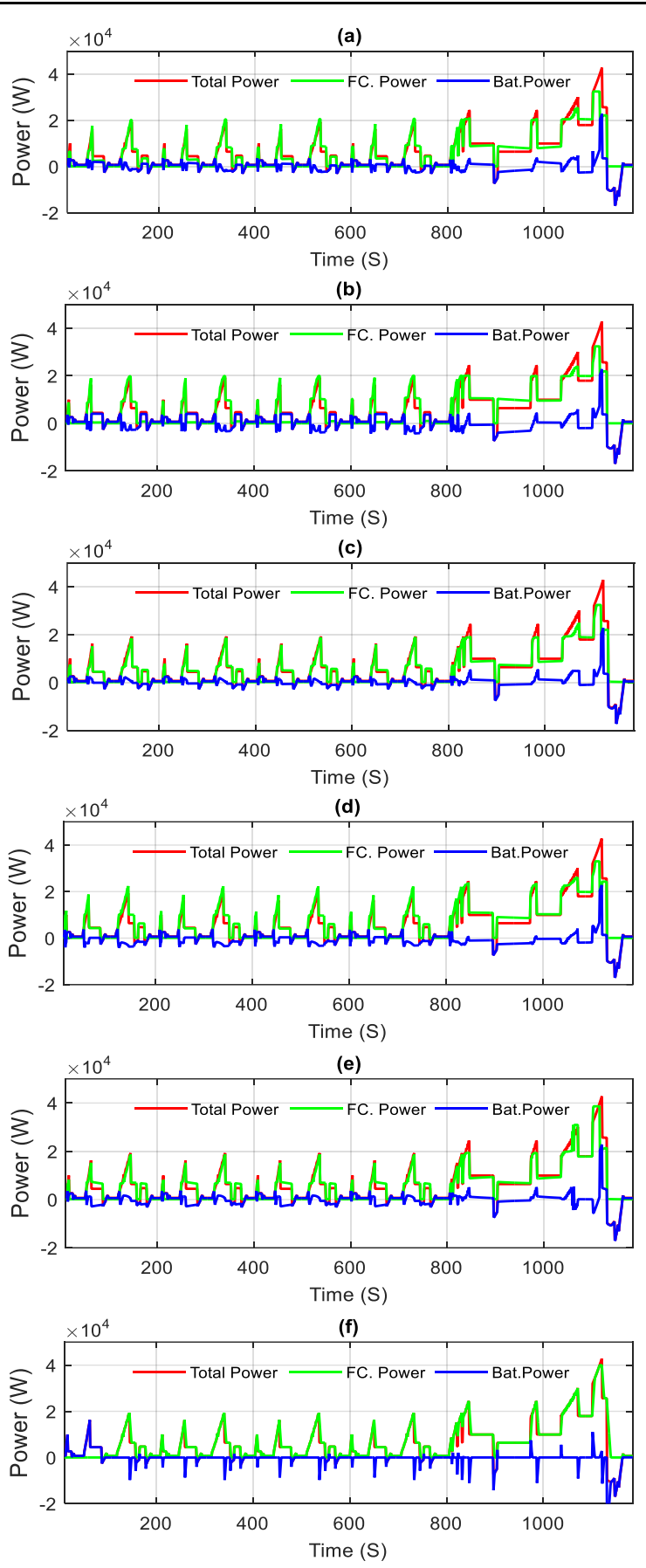

Fig. 10. Power distributions of all EMS models under NEDC: (a) FUZ.TUN (UDDS) (b) FUZ.TUN (NEDC)
(c) FUZ.TUN (HWFET)
(d) FUZ.TUN (WLTP)
(e) FUZ.TUN (MULTI)
(f) PTC_ADV
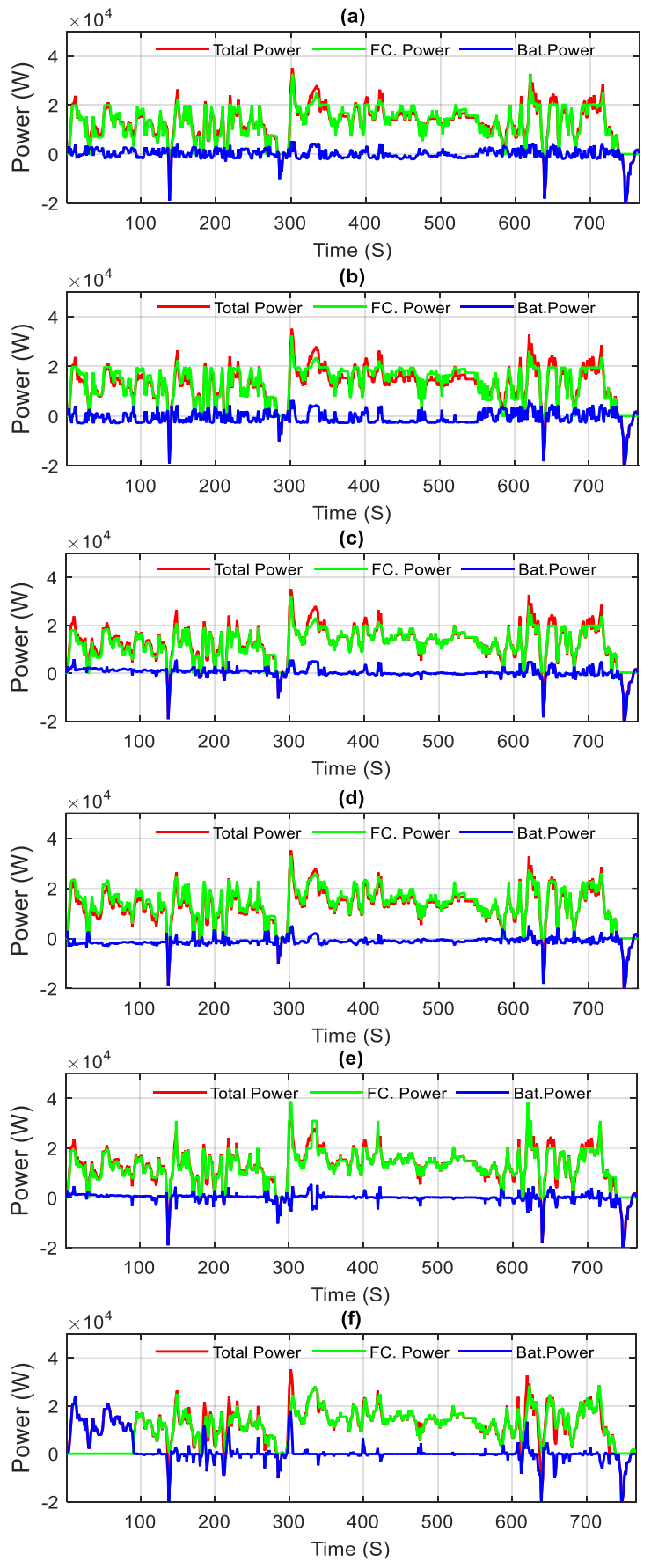

Fig. 11. Power distributions of all EMS models under HWFET: (a) FUZ.TUN (UDDS) (b) FUZ.TUN (NEDC)
(c) FUZ.TUN (HWFET)
(d) FUZ.TUN (WLTP)
(e) FUZ.TUN (MULTI)
(f) PTC_ADV 

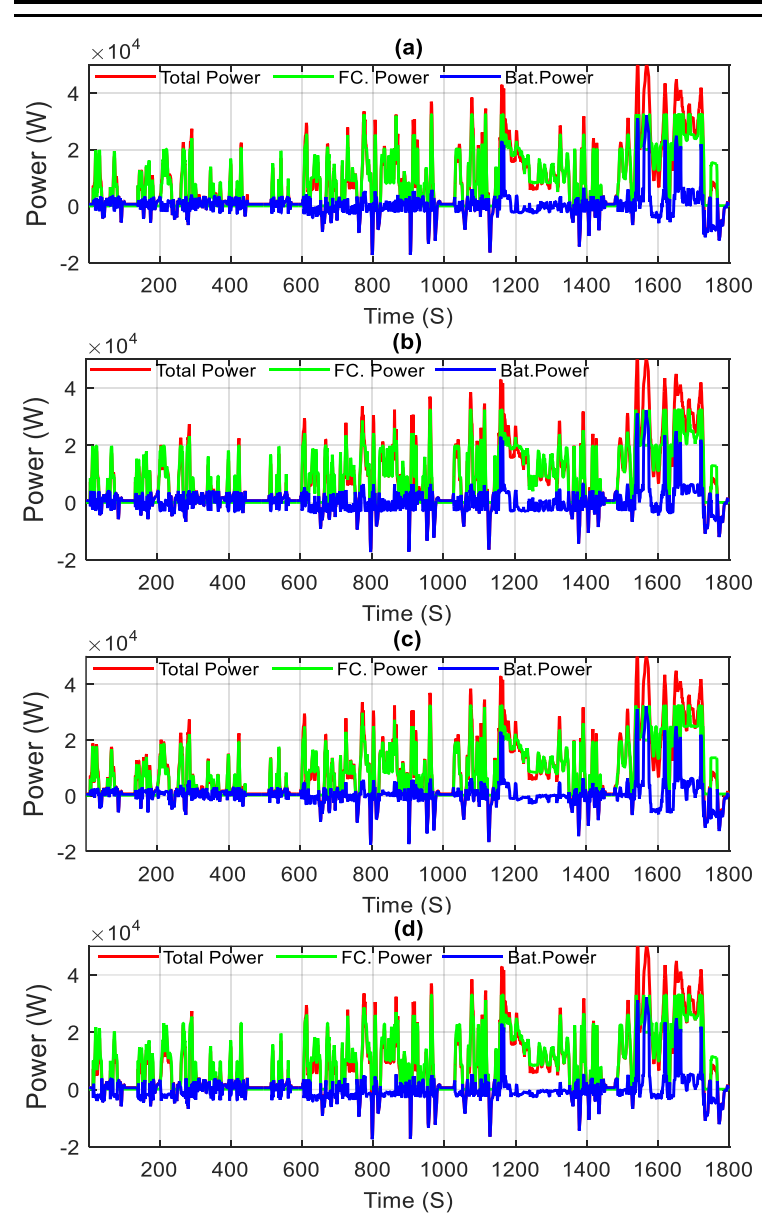

(e)

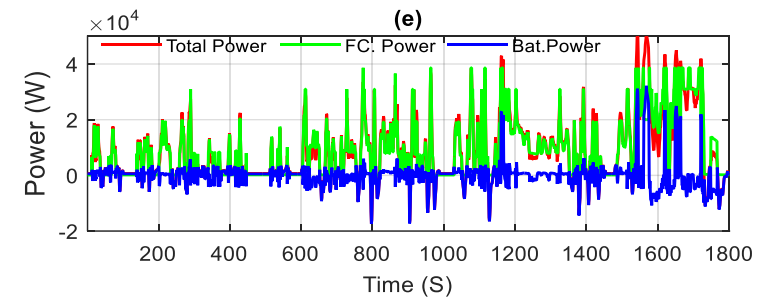

(f)

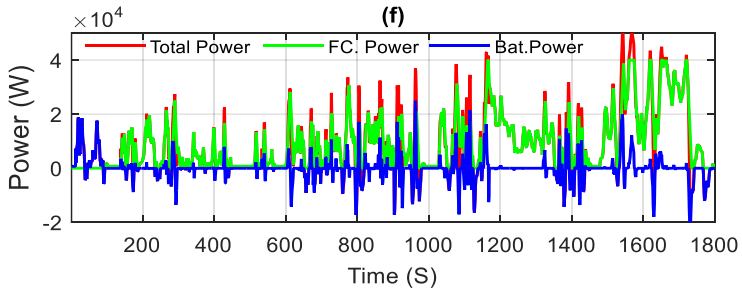

Fig. 12. Power distributions of all EMS models under WLTP Class 3 :
(a) FUZ.TUN (UDDS)
(b) FUZ.TUN (NEDC)
(c) FUZ.TUN (HWFET)
(d) FUZ.TUN (WLTP)
(e) FUZ.TUN (MULTI)
(f) PTC_ADV

Fig. 13-16 show the battery SOC trajectories of the different models under UDDS, NEDC, HWFET and WLTP, respectively. It can be seen that all SOC curves for all EMSs remain in the allowable range through all the cycles. The SOC curves in the case of FUZ.TUNED under UDDS, NEDC, HWFET and MULTI profiles are relatively close. It also can be seen that the SOC under the FUZ.TUN (MULTI) slightly diverges from the initial SOC through all driving cycles. The $\triangle \mathrm{SOC}$ is maintained by FUZ.TUN (MULTI) over all profiles as well.
The FUZ.TUN (UDDS) also maintains the $\triangle \mathrm{SOC}$ limits under UDDS, NEDC and WLTP.

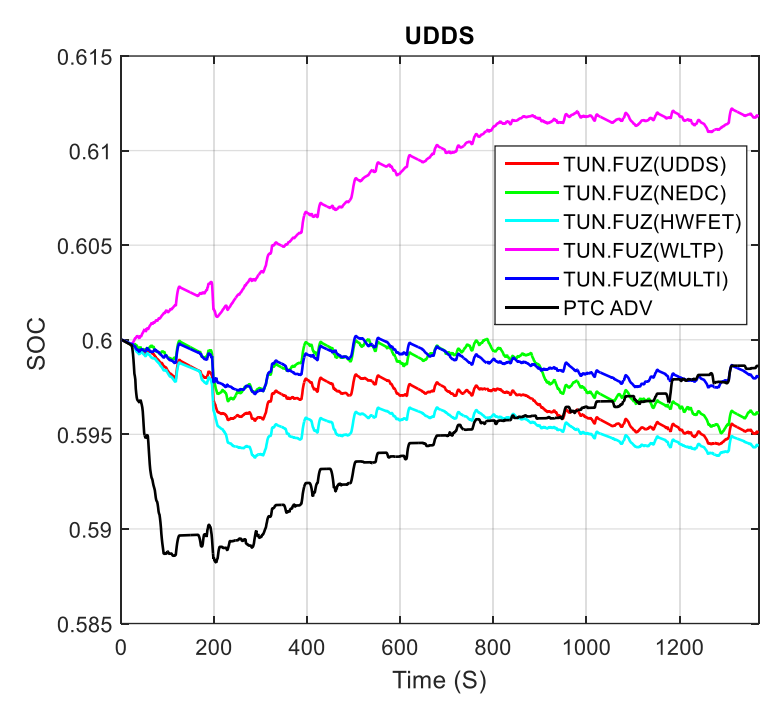

Fig. 13. SOC Trajectories of all models under UDDS

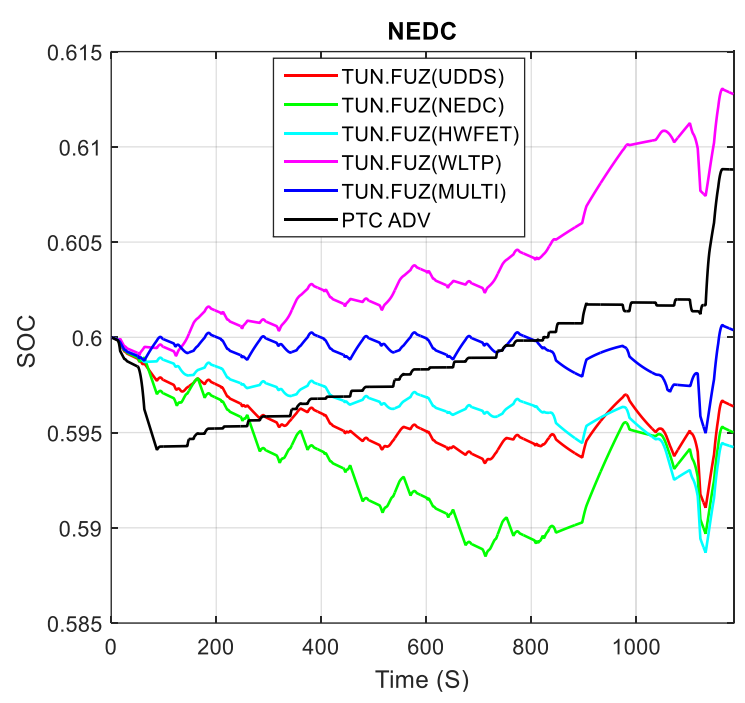

Fig. 14. SOC Trajectories of all EMS models under NEDC

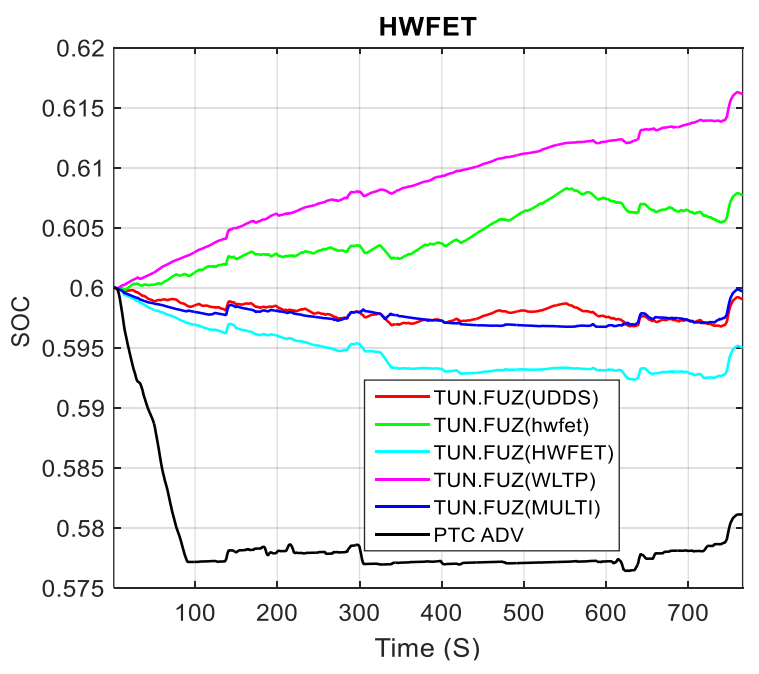

Fig. 15. SOC Trajectories of all EMS models under HWFET 
Tifour B., Boukhnifer M., Hafaifa A., Tanougast C.: Monitoring and control of energy management system ...

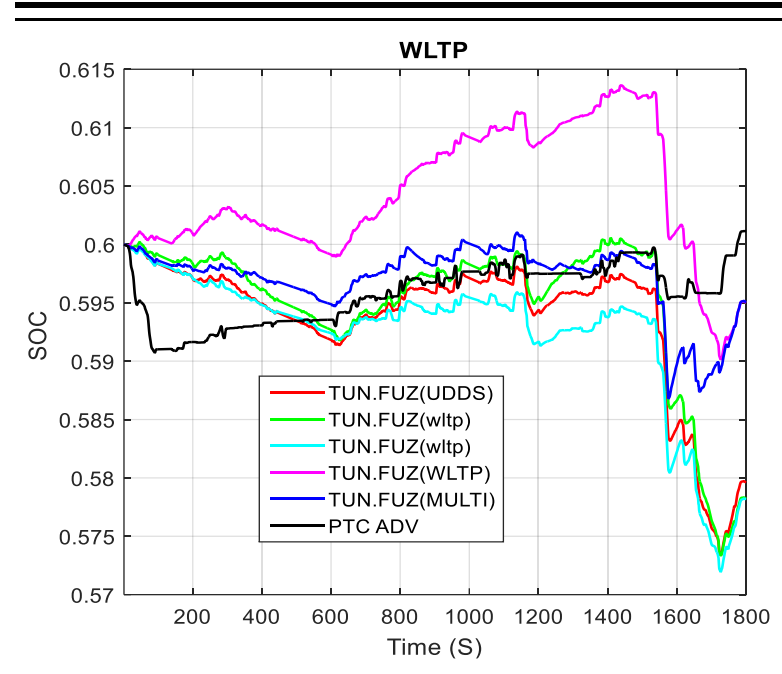

Fig. 16. SOC Trajectories of all EMS models under WLTP Class 3

Fig. 17-20 present the required speed curves and the actual speed response, they are identical, which indicates that the dynamic performance is preserved by all models whatever the driving profile.
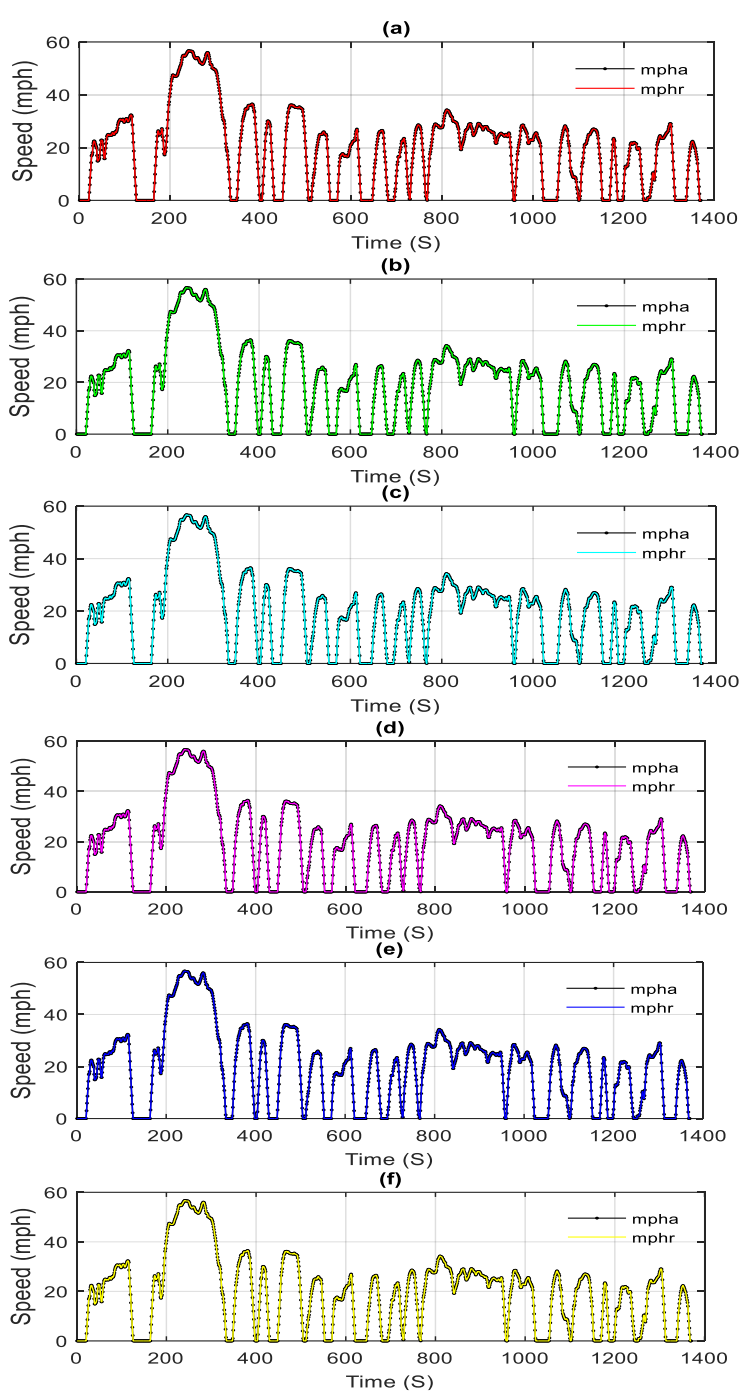

Fig. 17. The required and the actual speed (UDDS):
(a) FUZ.TUN (UDDS)
(b) FUZ.TUN (NEDC)
(c) FUZ.TUN (HWFET)
(d) FUZ.TUN (WLTP)
(e) FUZ.TUN (MULTI)
(f) PTC_ADV

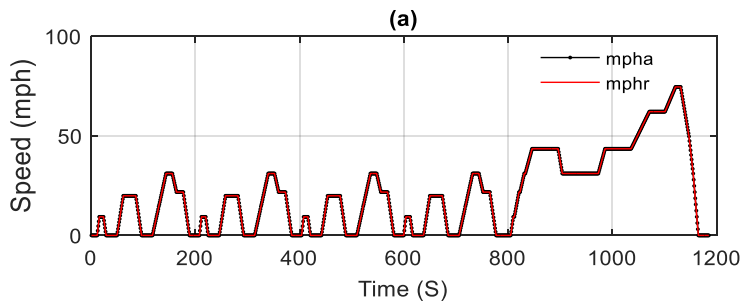

(b)

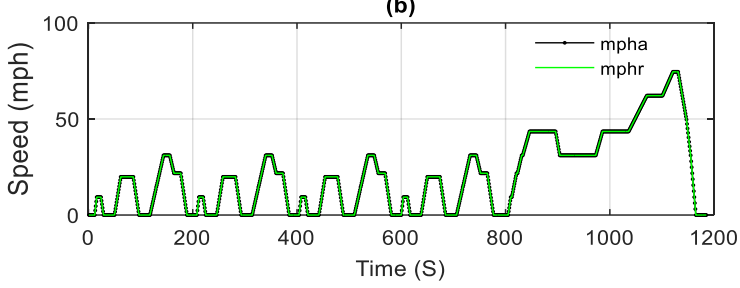

(c)
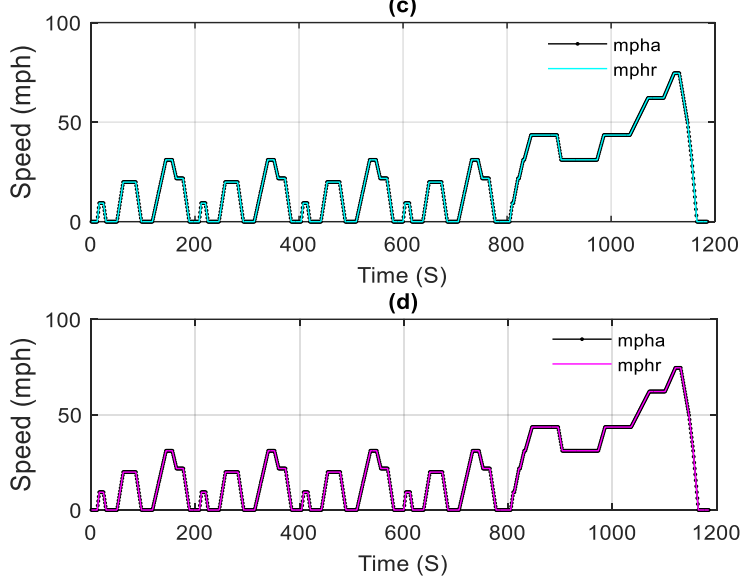

(e)

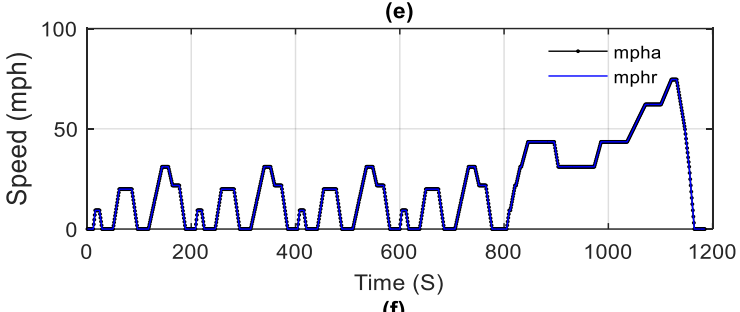

(f)

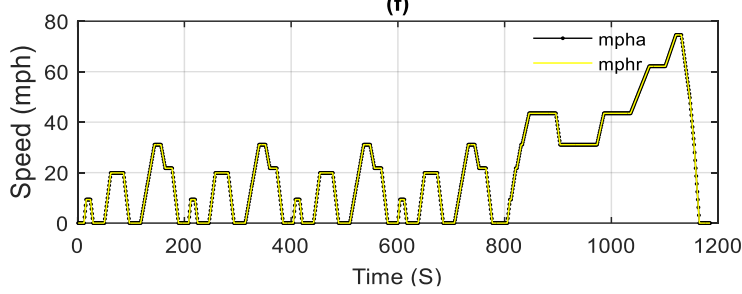

Fig. 18. The required and the actual speed (NEDC):
(a) FUZ.TUN (UDDS)
(b) FUZ.TUN (NEDC)
(c) FUZ.TUN (HWFET)
(d) FUZ.TUN (WLTP)
(e) FUZ.TUN (MULTI)
(f) PTC_ADV 

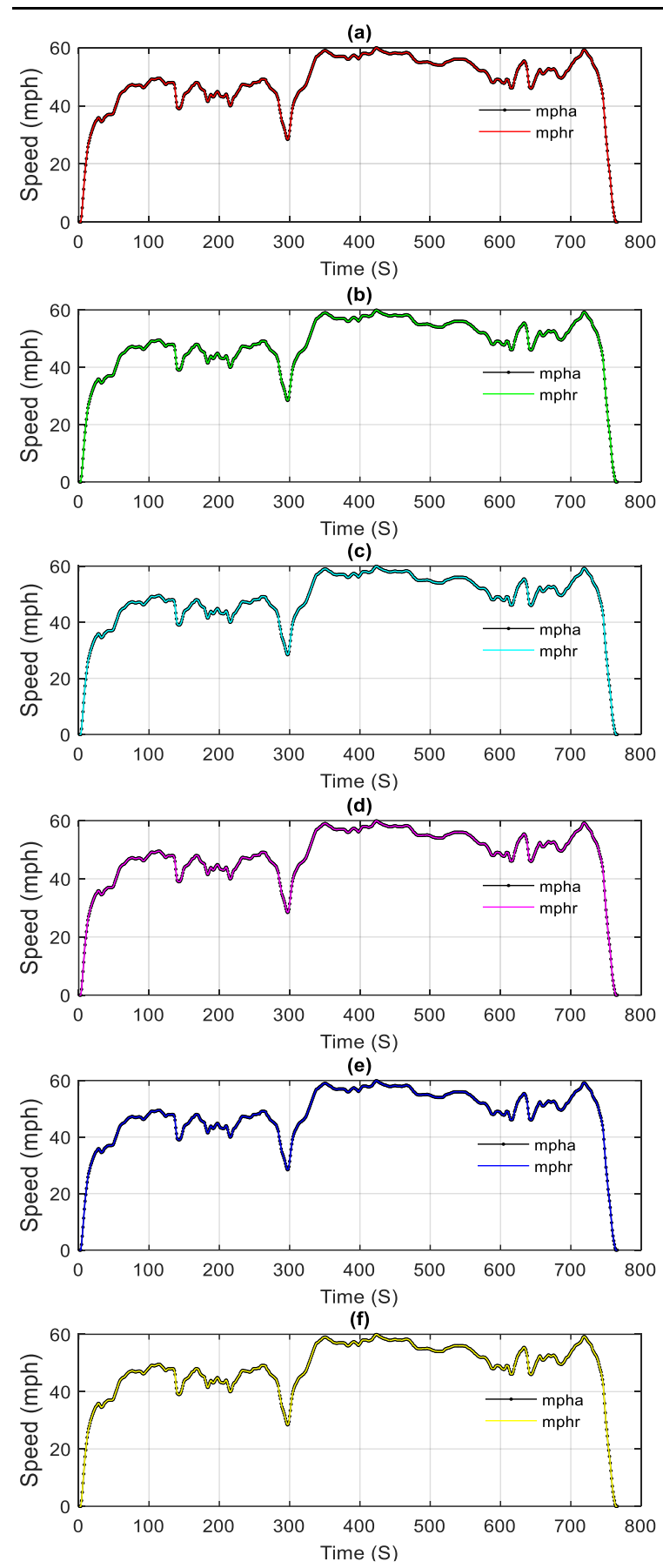

Fig. 19. The required and the actual speed (HWFET):
(a) FUZ.TUN (UDDS)
(c) FUZ.TUN (HWFET)
(b) FUZ.TUN (NEDC)
(e) FUZ.TUN (MULTI)
(d) FUZ.TUN (WLTP)
(f) PTC_ADV

Table 5. summarizes the fuel economy MPG, the Standard Deviation of the SOC (SD SOC), the $\triangle$ SOC and the overall efficiency of the whole system from the different models. The overall efficiency is calculated by the following formula [20]:

$$
\text { Eff } f_{\text {Overall }}=\frac{\text { Aero }+ \text { Rolling }}{\text { Fuel_in-ess_stored }}
$$

where Aero is the loss due to aerodynamic drag on the vehicle in Kilo-joules, Rolling is the total energy required for the vehicle to overcome the rolling resistance, Fuel_in is the total energy delivered by the fuel cell over the drive cycle and ess_stored is the useful energy leaving the batteries over the drive cycle.
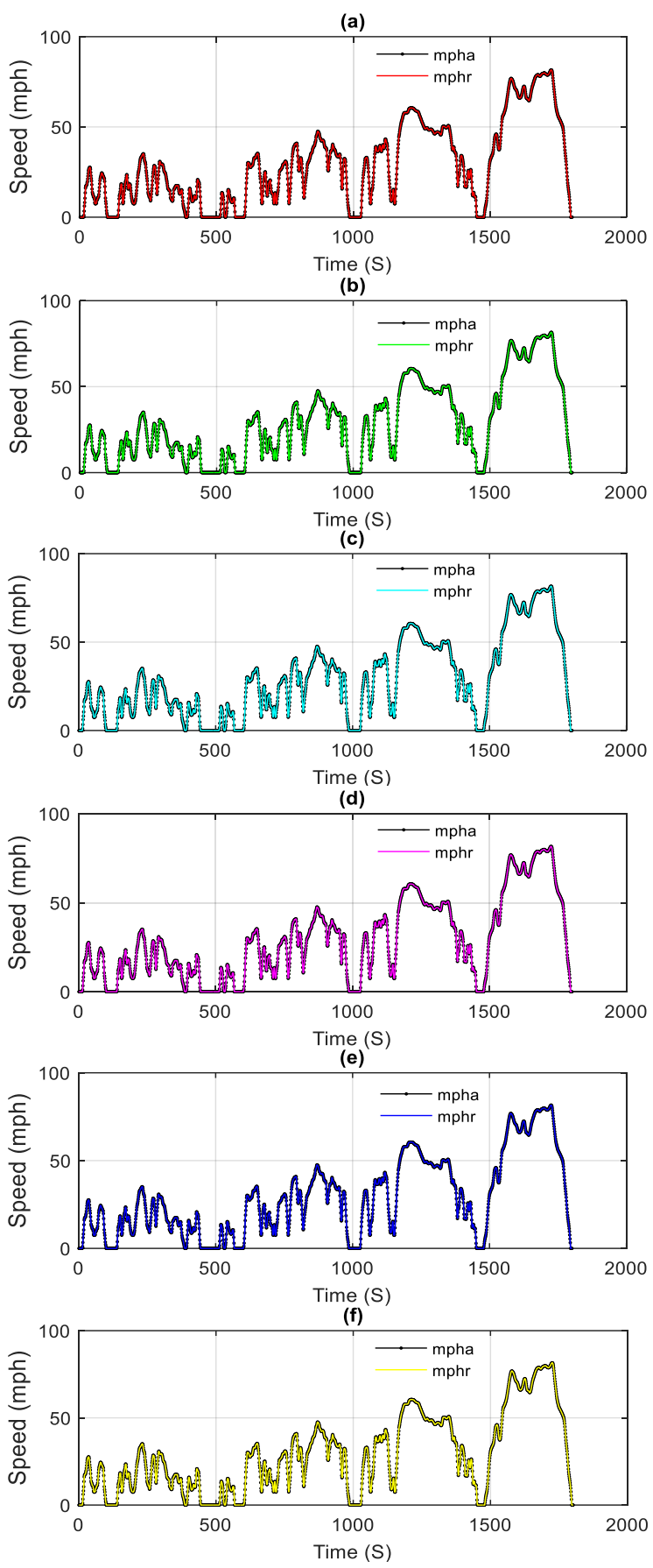

Fig. 20. The required and the actual speed (WLTP) Class3
(a) FUZ.TUN (UDDS)
(b) FUZ.TUN (NEDC)
(c) FUZ.TUN (HWFET)
(d) FUZ.TUN (WLTP)
(e) FUZ.TUN (MULTI)
(f) PTC $A D V$

To avoid the effect of the initial SOC on the fuel economy calculation, advisor provides a tool to correct the fuel economy within a tolerance that can be specified by the user. Hence the tolerance is chosen to be identical to the $\Delta \mathrm{SOC}$ constraint. 
Tifour B., Boukhnifer M., Hafaifa A., Tanougast C.: Monitoring and control of energy management system ...

Table 5. Fuel economy, SD SOC, $|\Delta \mathrm{SOC}|$, and overall efficiency results of the different EMSs over different driving cycles

\begin{tabular}{|c|c|c|c|c|c|}
\hline EMSs & Parameters & UDDS & NEDC & HWFET & WLTP \\
\hline \multirow{4}{*}{$\begin{array}{l}\text { FUZ. } \\
\text { TUN } \\
\text { (UDDS) }\end{array}$} & MPG & 3.8707 & 3.9025 & 4.7456 & 3.9214 \\
\hline & SD SOC & 0.001 & 0.002 & 0.001 & 0.006 \\
\hline & $|\Delta \mathrm{SOC}|$ & 0.005 & 0.004 & 0.001 & 0.020 \\
\hline & $\begin{array}{l}\text { Overall } \\
\text { Eff. }\end{array}$ & 0.174 & 0.220 & 0.328 & 0.277 \\
\hline \multirow{4}{*}{$\begin{array}{l}\text { FUZ. } \\
\text { TUN } \\
\text { (NEDC) }\end{array}$} & MPG & 3.8451 & 3.9529 & 4.6639 & 3.9364 \\
\hline & SD SOC & 0.001 & 0.003 & 0.003 & 0.003 \\
\hline & $|\Delta \mathrm{SOC}|$ & 0.004 & 0.005 & 0.008 & 0.022 \\
\hline & $\begin{array}{l}\text { Overall } \\
\text { Eff. }\end{array}$ & 0.174 & 0.222 & 0.322 & 0.278 \\
\hline \multirow{4}{*}{$\begin{array}{l}\text { FUZ. } \\
\text { TUN } \\
\text { (HWFET) }\end{array}$} & MPG & 3.7559 & 3.8200 & 4.8436 & 3.9004 \\
\hline & SD SOC & 0.001 & 0.002 & 0.002 & 0.002 \\
\hline & $|\Delta \mathrm{SOC}|$ & 0.006 & 0.006 & 0.005 & 0.022 \\
\hline & $\begin{array}{l}\text { Overall } \\
\text { Eff. }\end{array}$ & 0.174 & 0.221 & 0.331 & 0.277 \\
\hline \multirow{4}{*}{$\begin{array}{l}\text { FUZ. } \\
\text { TUN } \\
\text { (WLTP) }\end{array}$} & MPG & 3.7252 & 3.7527 & 4.6396 & 3.9836 \\
\hline & SD SOC & 0.004 & 0.004 & 0.004 & 0.004 \\
\hline & $|\Delta \mathrm{SOC}|$ & 0.012 & 0.013 & 0.016 & 0.005 \\
\hline & $\begin{array}{l}\text { Overall } \\
\text { Eff. }\end{array}$ & 0.168 & 0.212 & 0.317 & 0.272 \\
\hline \multirow{4}{*}{$\begin{array}{l}\text { FUZ. } \\
\text { TUN } \\
\text { (MULTI) }\end{array}$} & MPG & 3.7958 & 3.8032 & 4.7324 & 3.9436 \\
\hline & SD SOC & 0.001 & 0.001 & 0.001 & 0.001 \\
\hline & $|\Delta \mathrm{SOC}|$ & 0.002 & 0.000 & 0.000 & 0.005 \\
\hline & $\begin{array}{l}\text { Overall } \\
\text { Eff. }\end{array}$ & 0.172 & 0.218 & 0.328 & 0.269 \\
\hline \multirow{4}{*}{$\begin{array}{l}\text { PTC. } \\
\text { ADV }\end{array}$} & MPG & 3.7006 & 3.7232 & 4.7176 & 3.8225 \\
\hline & SD SOC & 0.003 & 0.003 & 0.003 & 0.003 \\
\hline & $|\Delta \mathrm{SOC}|$ & 0.001 & 0.009 & 0.019 & 0.001 \\
\hline & $\begin{array}{l}\text { Overall } \\
\text { Eff. }\end{array}$ & 0.171 & 0.213 & 0.340 & 0.266 \\
\hline
\end{tabular}

\section{CONCLUSION}

In this work, an EMS based first order Sugeno fuzzy for FCHEV was developed, a PSO was used for monitoring and optimization of the fuzzy parameters under different conditions in order to find the best sets that can achieve the best fuel economy considering the battery SOC maintenance. This study focused on the results issued from optimization under a particular condition and the results issued from optimization under multiple conditions. Results showed that the fuel economy improved in comparison with the PTC.ADV under all conditions, as well as the overall efficiency in most conditions. It also showed that tuning the fuzzy EMS under one condition cannot guarantee the same performance in terms of battery SOC when it is tested under another condition. However, if it is tuned under multiple conditions, it can achieve a good fuel economy with smooth SOC variations and a low $\triangle S O C$ which are beneficial to extend the battery life. In future work, a multi objective particle swarm optimization (MOPSO) will be applied to the proposed model with consideration of the sources' sizing. As this methodology was successful for the considered driving conditions, more driving profiles will be involved in the optimization process. Moreover, a real implementation to validate the fuzzy EMS controller will be performed.

\section{REFERENCES}

1. Bhatti A.R, Salam Z. A rule-based energy management scheme for uninterrupted electric vehicles charging at constant price using photovoltaic-grid system. Renewable Energy 2018; 125:384-400.

https://doi.org/10.1016/j.renene.2018.02.126

2. Cao Y, Yao H, Wang Z, Jermsittiparsert K, Yousefi $\mathrm{N}$. optimal designing and synthesis of a hybrid pv/fuel cell/wind system using meta-heuristics. Energy Reports 2020;6:1353-1362.

https://doi.org/10.1016/j.egyr.2020.05.017

3. Caux S, Hankache W, Fadel M, Hissel D. On-line fuzzy energy management for hybrid fuel cell systems, International Journal of Hydrogen Energy 2010;35(5):2134-2143.

https://doi.org/10.1016/j.ijhydene.2009.11.108

4. Chun-Yan L, Guo-Ping L. Optimal fuzzy power control and management of fuel cell/battery hybrid vehicles. Journal of power sources 2009; 192(2): 525-533.

https://doi.org/10.1016/j.jpowsour.2009.03.007

5. Guo J, He H, Peng J. Real-time energy management for plug-in hybrid electric vehicle based on economy driving pro system. Energy Procedia 2019;158:2689-2694. https://doi.org/10.1016/j.egypro.2019.02.023

6. Hemi H, Ghouili J, Cheriti A. A real time fuzzy logic power management strategy for a fuel cell vehicle. Energy Conversion and Management 2014; 80:63-70. https://doi.org/10.1016/j.enconman.2013.12.040

7. Kandidayeni M, Soleymani M, Ghadimi AA. Designing an optimal fuzzy controller for a fuel cell vehicle considering driving patterns. Scientia Iranica 2016;23(1):218-227.

https://dx.doi.org/10.24200/sci.2016.3827

8. Kennedy J, Eberhart R. Particle swarm optimization. In Proceedings of ICNN'95-International Conference on Neural Networks 1995; 4: 19421948. https://doi.org/10.1109/ICNN.1995.488968

9. Li Q, Chen W, Li Y, Liu S, Huang J. Energy management strategy for fuel cell/battery/ ultracapacitor hybrid vehicle based on fuzzy logic. International Journal of Electrical Power \& Energy Systems. 2012;43(1):514-525.

https://doi.org/10.1016/j.ijepes.2012.06.026

10. Mehta R, Verma P, Srinivasan D, Yang J. Doublelayered intelligent energy management for optimal integration of plug-in electric vehicles into distribution systems. Applied Energy 2019; 233/2341:146-155

https://doi.org/10.1016/j.apenergy.2018.10.008

11. Michalczuk M, Ufnalski B, Grzesiak L.M. Particle swarm optimization of the fuzzy logic controller for a hybrid energy storage system in an electric car. 2016 18th European Conference on Power Electronics and Applications. EPE'16 ECCE Europe:1-10. https://doi.org/10.1109/EPE.2016.7695387

12. Odeim F, Roes J, Wülbeck L, Heinzel A. Power management optimization of fuel cell/battery hybrid vehicles with experimental validation. Journal of 
Power Sources. 2014;252:333-343.

https://doi.org/10.1016/j.jpowsour.2013.12.012

13. Ouddah N, Boukhnifer M, Raisemche A, Two control energy management schemes for electrical hybrid vehicle, 10th IEEE International MultiConferences on Systems, Signals \& Devices 2013 (SSD13)https://doi.org/10.1109/SSD.2013.6564135

14. Radaideh MI, Radaideh MI, Kozlowski T. Design optimization under uncertainty of hybrid fuel cell energy systems for power generation and cooling purposes. International Journal of Hydrogen Energy 2020;45(3):2224-2243

https://doi.org/10.1016/j.ijhydene.2019.11.046

15. Ravey A, BlunierB, Miraoui A.Control Strategies for Fuel-Cell-Based Hybrid Electric Vehicles: From Offline to Online and Experimental Results. IEEE Transactions on Vehicular Technology 2012; 61(6): 2452-245.

https://doi.org/10.1109/TVT.2012.2198680

16. Satyapal Sunita. Hydrogen and Fuel Cells Overview, 12-Apr-2017 [online]. Available:

https://www.energy.gov/sites/prod/files/2017/06/f34 /fcto-h2-fc-overview-dla-worldwide-energy-conf2017-satyapal.pdf [Accessed- 24 - Mar-2019]

17. Sedighizadeh M, Esmaili M, Mohammadkhani N. Stochastic multi-objective energy management in residential microgrids with combined cooling, heating, and power units considering battery energy storage systems and plug-in hybrid electric vehicles. Journal of Cleaner Production 2018; 195: 301-317 https://doi.org/10.1016/j.jclepro.2018.05.103

18. Sulaiman N. Hannan MA, Mohamed A, Majlan EH, Wan Daud WR. A review on energy management system for fuel cell hybrid electric vehicle: Issues and challenges. Renewable and Sustainable Energy Reviews 2015;52:802-814. https://doi.org/10.1016/j.rser.2015.07.132

19. Tanc B, Arat HT, Baltacıoglu E, Aydın K. Overview of the next quarter century vision of hydrogen fuel cell electric vehicles. International Journal of Hydrogen Energy 2019; 44: 10120-10128. https://doi.org/10.1016/j.ijhydene.2018.10.112

20. The National Renewable Energy Laboratory. USA.2003.ADVISOR Advanced Vehicle Simulator, advisor-2003-00-r0116. Available: https://sourceforge.net/projects/adv-vehiclesim/files/ADVISOR/ [Accessed- 01-27/ Mar-2019]

21. Tremblay O, Dessaint LA. Experimental validation of a battery dynamic model. World Electric Vehicle Journal 2009;3:1-10.

https://doi.org/10.3390/wevj3020289

22. Wang Y, Moura SJ, Advani SG, Prasad AK. Power management system for a fuel cell/battery hybrid vehicle incorporating fuel cell and battery degradation. International Journal of Hydrogen Energy 2019;44(16):8479-8492. https://doi.org/10.1016/j.ijhydene.2019.02.003

23. Wipke KB, Cuddy MR, Burch SD. ADVISOR 2.1: A user-friendly advanced powertrain simulation using a combined backward/forward approach. IEEE transactions on vehicular technology 1999; 48(6): 1751-1761. https://doi.org/10.1109/25.806767

24. Wu X, Zhang K, Cheng M. Optimal control of constrained switched systems and application to electrical vehicle energy management. Nonlinear Analysis: Hybrid Systems 2018; 30: 171-188. https://doi.org/10.1016/j.nahs.2018.05.006

25. Zhang G, Chen W, Li Q. Modeling, optimization and control of a FC/battery hybrid locomotive based on ADVISOR. International Journal of Hydrogen Energy 2017;42(29):18568-18583.

https://doi.org/10.1016/j.ijhydene.2017.04.172

26. Zhang $\mathrm{R}$, Tao J. Ga-Based fuzzy energy management system for $\mathrm{Fc} / \mathrm{Sc}$-Powered $\mathrm{HEV}$ considering $\mathrm{H} 2$ consumption and load variation. EEE Transactions on Fuzzy Systems 2018; 26(4): 1833-1843. https://doi.org/10.1109/TFUZZ.2017.2779424

Received 2020-02-22

Accepted 2020-06-15

Available online 2020-06-17
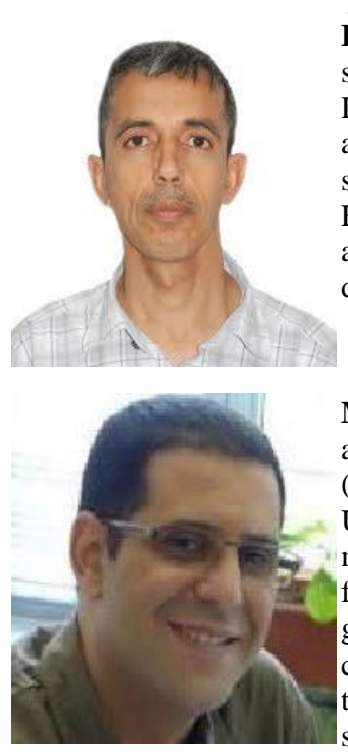

Moussa BOUKHNIFER is an Associate Professor HDR (SMIEEE) at Lorraine University (France). His main research interests are focused on energy management, diagnosis and FTC control with its applications to electrical and autonomous system.

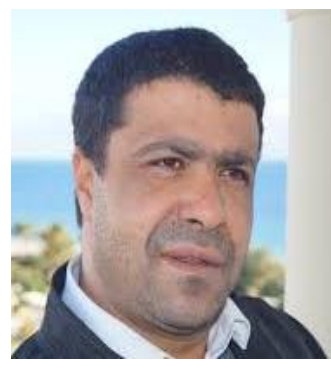

Ahmed HAFAIFA Professor at the University of Djelfa. His research area of interests includes the modelling and control in industrial systems, the diagnosis and new reliability engineering, fault detection and isolation in industrials process, intel-igent system based on fuzzy logic and neural networks.

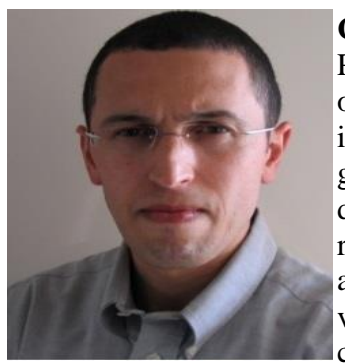

Camel TANOUGAST Professor at the University of Lorraine France. His interests include reconfigurable systems and NoCs, design and implem-entation real time processing architectures, computing vision, image processing, cryptography and the Digital Television Broadcast. 